\title{
ORC-dependent and origin-specific initiation of DNA replication at defined foci in isolated yeast nuclei
}

\author{
Philippe Pasero, Diego Braguglia, ${ }^{1}$ and Susan M. Gasser ${ }^{2}$ \\ Swiss Institute for Experimental Cancer Research, CH-1066 Epalinges/Lausanne, Switzerland
}

\begin{abstract}
We describe an in vitro replication assay from yeast in which the addition of intact nuclei to an S-phase nuclear extract results in the incorporation of deoxynucleotides into genomic DNA at spatially discrete foci. When BrdUTP is substituted for ITTP, part of the newly synthesized DNA shifts to a density on CsCl gradients, indicative of semiconservative replication. Initiation occurs in an origin-specific manner and can be detected in $G_{1}-$ or S-phase nuclei, but not in $G_{2}$-phase or mitotic nuclei. The S-phase extract contains a heatand 6-DMAP-sensitive component necessary to promote replication in $G_{1}$-phase nuclei. Replication of nuclear DNA is blocked at the restrictive temperature in an orc2-1 mutant, and the inactive Orc2p cannot be complemented in trans by an extract containing wild-type ORC. The initiation of DNA replication in cln-deficient nuclei blocked in $G_{1}$ indicates that the ORC-dependent prereplication complex is formed before Start. This represents the first nonviral and nonembryonic replication system in which DNA replication initiates in an ORC-dependent and origin-specific manner in vitro.
\end{abstract}

[Key Words: DNA replication; yeast; nuclear organization; replication foci; ORC]

Received January 30, 1997; revised version accepted April 24, 1997.

Replication of the genetic material must be achieved once per cell cycle, and with high fidelity and speed, to avoid deleterious consequences for the progeny of the cell. These important requirements imply a complex degree of coordination between cis-acting sequences and regulatory factors involved in this process. In eukaryotic cells, DNA replication initiates at multiple defined sites in the genome, called origins of replication (for review, see Coverley and Laskey 1994; Hamlin and Dijkwel 1995), at which the simultaneous engagement of polymerases ensures coordinated initiation events and a rapid replication of large chromosomes. Critical control mechanisms that are not yet understood fully, ensure that the genome is replicated once and only once per cell cycle (for review, see Muzi-Falconi et al. 1996; Donovan and Diffley 1996; Kearsey et al. 1996).

Thanks largely to yeast genetics, the sequences and factors that control the initiation of DNA replication have been extensively characterized. Two-dimensional gel techniques have shown that ARS (autonomously replicating sequence) elements allow cell cycle-controlled plasmid replication, and function as genomic origins of replication in budding yeast (Brewer and Fangman 1987; Huberman et al. 1987). On average, ARS elements are

\footnotetext{
${ }^{1}$ Present address: Gene Therapy Center, University of Lausanne Medical School, CHUV, CH-1011 Lausanne, Switzerland.

${ }^{2}$ Corresponding author.

E-MAIL sgasser@eliot.unil.ch; FAX 41216526933.
}

found once per $36 \mathrm{~kb}$ (Campbell and Newlon 1991), yet chromosomal context and local chromatin structure also regulate initiation, because not all ARS elements are active origins in their genomic location (for review, see Fangman and Brewer 1991; Coverley and Laskey 1994). The origin recognition complex (ORC), a six-subunit complex that recognizes the 11-bp ARS consensus (Bell and Stillman 1992), is bound at both active and inactive origins throughout the cell cycle (Diffley et al. 1994). Strains that carry temperature-sensitive alleles of $O R C 2$ and ORC5 show defects in the maintenance of ARS-containing plasmids, incomplete DNA replication at nonpermissive temperature, and a reduced efficiency of origin firing, consistent with a role in the initiation of genomic DNA replication (Bell et al. 1993; Micklem et al. 1993, Fox et al. 1995; Liang et al. 1995). Recent studies on the temperature-sensitive orp1-4 mutant of Schizosaccharomyces pombe, defective in the largest subunit of ORC, show that spores completely lacking orp $1^{+}$arrest with a 1N DNA content, confirming its role in the $\mathrm{G}_{1} / \mathrm{S}$ transition (Grallert and Nurse 1996).

Because the ORC complex remains bound at origins throughout the cell cycle (Diffley et al. 1994), events other than ORC binding are required to trigger the initiation of DNA replication. A two-step process for the activation of origins has been proposed (Coverley and Laskey 1994; Nasmyth 1996). In yeast cells, the first step requires transformation of the postreplicative ORC footprint into a prereplicative state (Donovan and Diffley 
1996). This requires the synthesis of Cdc6p, a protein that interacts with ORC, before activation of the Clb5/ Cdk1 complex at the $G_{1} / S$ transition (Liang et al. 1995; Cocker et al. 1996; Piatti et al. 1996; for review, see Heichman 1996; Kearsey et al. 1996). Consistent with this model, the initiation of DNA replication in Xenopus extracts also requires the Xenopus homolog of Cdc $6 p$ (Coleman et al. 1996). Other candidate regulatory factors acting at origins of replication include the MCM /Minichromosome maintenancel family of genes, the mutation of which reduces the efficiency of replication from both genomic and plasmid-borne origins in yeast (for review, see Tye 1994; Romanowski and Madine 1996). A requirement for both $\mathrm{ORC}$ and the $\mathrm{XMcm} 3$ protein was confirmed for the replication of sperm nuclei in Xenopus egg extracts (Coleman et al. 1996; Romanowski et al. 1996; Rowles et al. 1996). The final stimulation of initiation at replication-competent origins is promoted by the activation of an S-phase promoting factor, which in yeast requires both the $\mathrm{Clb} / \mathrm{Cdk} 1$ and Dbf4/Cdc 7 kinase complexes (Jackson et al. 1993; Schwob and Nasmyth 19931.

Studies in higher eukaryotic cells suggest that nuclear organization may be a prerequisite for replication as well. In Xenopus eggs or egg extracts, the input DNA must be preassembled in a pseudonuclear structure to permit replication, and the integrity of the nuclear envelope is necessary for restricting DNA replication to one round only (Blow and Laskey 1986, 1988). In reconstituted pseudonuclei, DNA synthesis was found to occur in discrete foci, each of which represents a clustering of $\sim 300$ replication forks, resembling the foci observed in replicating mammalian nuclei in vivo (Nakamura et al. 1986; Cox and Laskey 1991; Newport and Yan 1996).

To link the genetics of $\mathrm{G}_{1} / \mathrm{S}$ control-which is well characterized in yeast-with the structural observations of replication foci made in Xenopus or mammalian systems, we have developed an in vitro system for DNA replication based on yeast nuclear extracts. Using nuclei isolated from yeast cells synchronized in S-phase, we prepare nuclear extracts that support a low level of plasmid replication, as monitored by a base substitution and density shift analysis, the appearance of replication intermediates on neutral-neutral two-dimensional (2D) gels, and sensitivity to mutations in the replicative polymerases $\delta, \alpha$, and primase (D. Braguglia, P. Pasero, B. Duncker, P. Heus, and S. Gasser, in prep.). However, the replication of a supercoiled plasmid in this soluble extract initiates at random sites within the plasmid in both the presence and absence of an intact ARS consensus, reminiscent of the sequence-independent initiation of plasmid replication observed in Xenopus extracts or in transformed mammalian tissue culture cells (Blow and Laskey 1986; Hyrien and Méchali 1992; for review, see Coverley and Laskey 1994).

To circumvent the random initiation that occurs on a naked plasmid, we have introduced isolated yeast nuclei into S-phase extracts, and have monitored replication of the genomic DNA in vitro. Derivatized dUTP is incorporated into genomic DNA in distinct foci, indicating that replication foci are not unique to metazoans. This occurs in $\mathrm{G}_{1}$ - or S-phase yeast nuclei, but not in $\mathrm{G}_{2}$ - or $M$-phase nuclei, and is aphidicolin-sensitive. Densityshift experiments confirm the presence of semiconservative DNA synthesis, whereas two-dimensional gel analyses indicate initiation events at or near the origin of replication (ARS) on plasmids carried in these nuclei. These criteria are consistent with bona fide replication of the yeast genomic DNA in vitro. Importantly, replication in $G_{1}$-phase nuclei is entirely dependent on ORC, being temperature-sensitive in orc2-1 nuclei. The fact that we cannot complement the orc2-1 defect in template nuclei with a wild-type S-phase extract, suggests an important role for ORC in the organization of the prereplication complex (pRC) in $G_{1}$-phase nuclei, whereas the immediate block to replication upon a temperature shift of preorganized orc2-1 nuclei, demonstrates the essential role of ORC in the initiation event.

\section{Results}

The incorporation of nucleotides occurs at discrete foci in isolated yeast nuclei

Our aim has been to establish an efficient in vitro system from yeast that supports both the initiation and elongation events of DNA replication, to analyze mutations that affect DNA replication on a biochemical level. We monitor the incorporation of a derivatized nucleotide, biotin-dUTP, in isolated yeast nuclei introduced into a S-phase nuclear extract, during and after $90 \mathrm{~min}$ at $25^{\circ} \mathrm{C}$ (see Materials and Methods). Biotin-dUTP incorporation is followed by reaction with avidin-FITC after depositing the nuclei on a microscope slide. As shown in the laser scanning microscopy images (Fig. 1A), a fraction of these nuclei, isolated from a nonsynchronized population of cells, shows discrete yellow foci of the biotindUTP signal within the general DNA stain [ethidium bromide (EtBr) red]. The biotin-dUTP (Fig. 1A) can be replaced by digoxigenin-derivatized dUTP (DIG-dUTP) and detected with FITC-tagged F(ab) fragments with identical results (bottom nucleus, Fig. 1C-E), ruling out that the focal staining pattern results from the aggregation of multivalent molecules. The peaks of incorporated label are three- to 10-fold higher than the low background signal within the nucleus (see Fig. 1E), and are absent in the presence of aphidicolin, which inhibits the three DNA polymerases implicated in genomic DNA replication (Fig. 1B). At longer incubation times, the incorporation of derivatized dUTP expands to produce a uniform FITC signal (e.g., upper nucleus, Fig. 1C-E), consistent with the hypothesis that these correspond to the replication foci seen in vertebrate nuclei (Nakamura et al. 1986; Cox and Laskey 1991). To demonstrate that the foci are within the nuclear spheres, we show nine partially overlapping focal sections scanning from the bottom to the top of the nucleus, revealing the existence of 15-20 sites of incorporation per nucleus (Fig. 1, DIGdUTP in G; DNA in F; and the merger in $H$ ). If the yeast genomic origins are distributed equally among these 
Figure 1. Replication in yeast nuclei is organized in discrete foci in vitro. (A) A confocal microscopy image of wild-type yeast nuclei incubated for $90 \mathrm{~min}$ in a nuclear extract containing biotin-dUTP, as described in Materials and Methods. The DNA was stained with $\mathrm{EtBr}$ (red), and the sites of incorporation of biotin-dUTP were detected with FITC-ExtrAvidin (green/yellow). About $40 \%$ of the cells were in $\mathrm{S}$ phase before nuclear isolation. (B) A reaction identical to that shown in $A$ was performed in the presence of $0.5 \mathrm{mg} / \mathrm{ml}$ of aphidicolin. Bar, $3 \mu \mathrm{m} .(C)$ High resolution image of two S-phase yeast nuclei labeled as in $A$, but using DIG-dUTP, revealed by FITCcoupled anti-DIG F(ab) fragments (green) and $\mathrm{EtBr}(\mathrm{red})$. Bar, $1 \mu \mathrm{m} .(D, E)$ Surface topography profiles of the red (DNA) and green (DIGdUTP) channels of the image in $C$ calculated with the Carl Zeiss LSM software. The blue indicates the basal nuclear fluorescence. $\mid F-$ $H$ ) Nine partially overlapping optical sections (0.3 $\mu \mathrm{m}$ each) through a yeast nucleus incubated as in $C .|F|$ The EtBr staining of the nuclear DNA. $|G|$ The DIG-dUTP visualized by FITC-anti-DIG F(ab). (H) Superposition of the two. Bar, $2 \mu \mathrm{m}$.
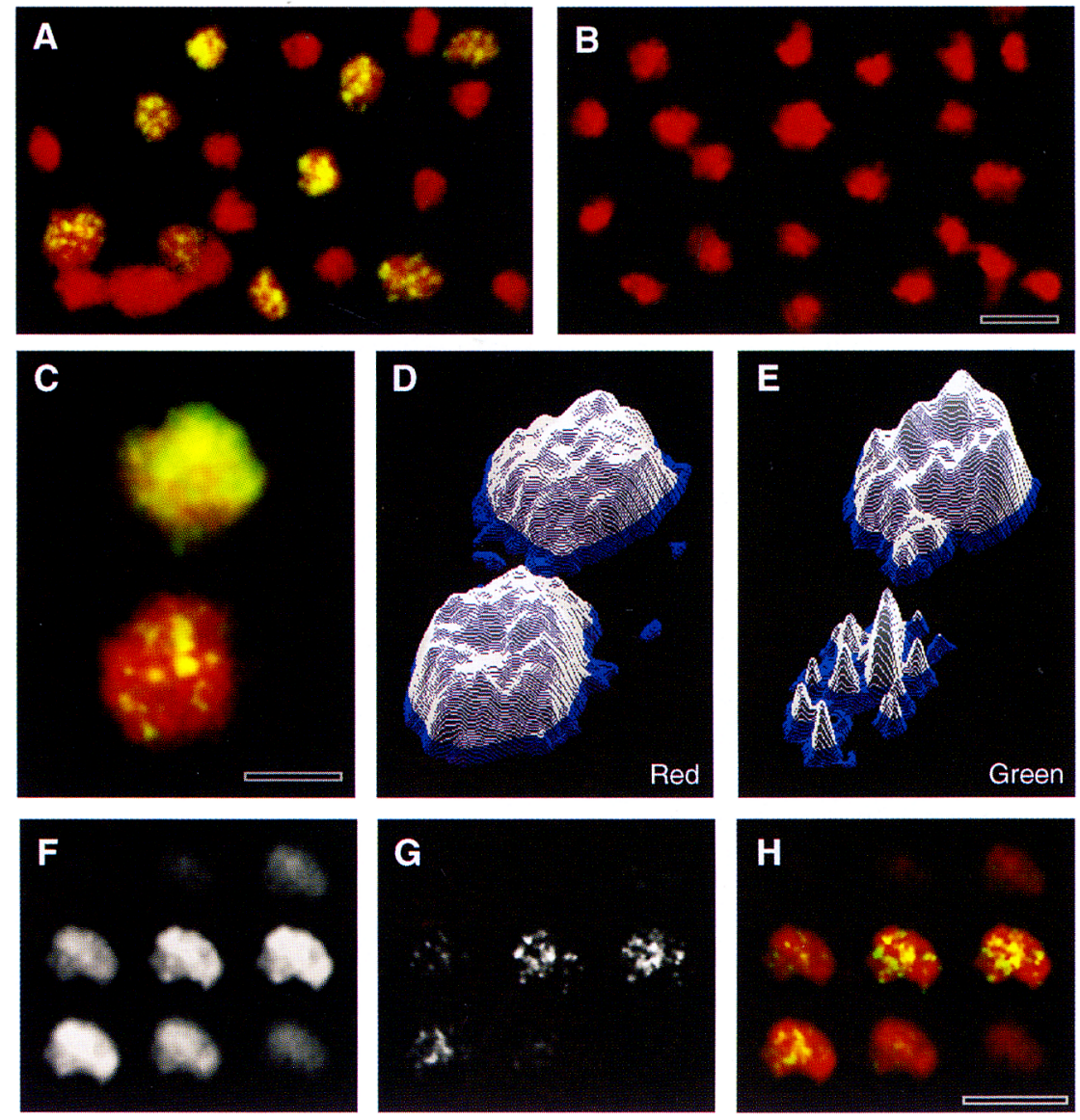

foci, each should contain roughly 20 bidirectional replication forks.

The incorporation of derivatized dUTP can be quantified in two ways. First, the fraction of nuclei containing foci can be calculated over several randomly chosen fields (usually scoring 400 nuclei). Second, the ratio of total FITC signal (DIG-dUTP) to EtBr signal (total DNA) can be determined, indicating the level of incorporation relative to nuclear DNA (see Materials and Methods). In a typical incubation using S-phase nuclei (e.g., Fig, 4G, below), $60 \%-70 \%$ of the nuclei show strong replication foci, whereas the rest fail to incorporate any label at all based on fluorescence detection. This assay for replication foci allows us to eliminate any background from contaminating free DNA or sheared nuclei, as fields of intact nuclei are analyzed, and free DNA does not adhere to the microscope slide. In some instances, the yeast were rendered deficient for mitochondrial DNA to avoid signals attributable to contaminating organelles, although this proved unnecessary. The appearance of nuclear DIG-dUTP foci is identical in $r h o^{+}$and $r h o^{\circ}$ cells (cf. Fig. 1 with Figs. 3,4,7, below).

\section{Quantitation of the in vitro DNA replication reaction}

In metazoans the appearance of replication foci has been shown to correlate with genomic replication (Newport and Yan 1996). To correlate the observed yeast foci with genomic replication, we monitored DNA synthesis by an independent technique based on $\left[\alpha-{ }^{32} \mathrm{P}\right] \mathrm{dATP}$ incorporation, which is quantified easily. When yeast nuclei are incubated in an S-phase extract in the presence of $\left[\alpha{ }^{32} \mathrm{P}\right] \mathrm{dATP}$ and analyzed by agarose gel electrophoresis, we observe the accumulation of label in high-molecularweight DNA (e.g., Fig. 5C, below). To calculate the amount of DNA synthesized, we determined the internal nuclear pool of dATP, the dilution factor for the radiolabeled AATP, the moles of DNA synthesized and moles of template DNA added (see Materials and Methods; Table 1). As expected, the extent of label incorporation depends on both the period of incubation and the ratio of nuclei to nuclear extract (Fig. 4I, below; data not shown). Typically, for $100 \mathrm{ng}$ of input genomic DNA (or $10^{7}$ nuclei) and a 90-min incubation, between 20-30 ng of newly synthesized DNA comigrate with the band of genomic DNA on the agarose gel. Incorporation generally increases significantly after a further $90 \mathrm{~min}$ (see S-phase nuclei in Fig. 4I, below; Table 1, samples 6,7).

The values listed in Table 1 represent a minimal estimate of total DNA synthesis, as they do not include the background of label incorporated into DNA fragments running below genomic DNA, a fraction that is likely to reflect repair synthesis on fragmented chromosomes. The rapid isolation of yeast nuclei for use as template 
Table 1. Quantitation of DNA synthesis

\begin{tabular}{llccc}
\hline & & \multirow{2}{*}{$\begin{array}{c}\text { Reaction } \\
\text { Experiment }\end{array}$} & \multicolumn{2}{c}{ DNA synthesized } \\
\cline { 4 - 5 } & Nuclei & min) & pmoles & ng \\
\hline 1 & S phase & 90 & 73 & 24 \\
2 & S phase & 90 & 83 & 28 \\
3 & S phase & 90 & 80 & 27 \\
4 & S phase & 90 & 75 & 25 \\
5 & S phase & 90 & 93 & 31 \\
6 & S phase & 90 & 57 & 19 \\
7 & S phase & 180 & 98 & 32 \\
8 & G $_{1}$ phase & 90 & 73 & 24 \\
9 & C $_{1}$ phase & 180 & 95 & 32 \\
10 & G $_{1}$ phase & 90 & 88 & 29 \\
\hline
\end{tabular}

In each experiment, $100 \mathrm{ng}$ equivalent of nuclei from GA-59 cells arrested in $G_{1}$ phase by $\alpha$-factor or released into $S$ phase, were incubated in a wild-type S-phase extract for 90 or $180 \mathrm{~min}$, as indicated. Samples 6 and 7, and samples 8 and 9 were sequential time points of one reaction. Replication assays and quantitation of $\left[\alpha-{ }^{32}\right.$ P]dATP incorporation into the high-molecularweight genomic DNA are described in Materials and Methods.

inevitably produces some nuclear lysis, resulting in variable levels of repair synthesis. Thus, total nucleotide incorporation reflects both repair synthesis and genomic replication. Nonetheless, when coupled with the appearance of DIG-dUTP foci, the fluctuation in $\left[\alpha{ }^{32} \mathrm{P}\right] \mathrm{dATP}$ incorporation above a background level does correlate with the relative efficency of replication, particularly within a given nuclear preparation (see Fig. 3D,E, below).

\section{BrdUTP incorporation confers a density shift on replicated genomic DNA}

To calculate the fraction of incorporated nucleotide that reflects semiconservative DNA replication, as opposed to patch- or gap-repair, we replaced dTTP by the heavy analog BrdUTP during the synthesis reaction, adding $\left[\alpha{ }^{32} \mathrm{P}\right] \mathrm{dATP}$ as a tracer. After a $180-\mathrm{min}$ incubation in extract, total DNA is isolated and analyzed by $\mathrm{CsCl}$ density gradient centrifugation, and the sedimentation of radiolabeled genomic DNA is determined. In the experiment using $G_{1}$-phase nuclei shown in Figure 2A lopen circles), $40 \%$ of radiolabeled DNA shifts to the position of fully substituted heavy-light DNA, a position confirmed by the sedimentation analysis of fully substituted M13 DNA (heavy-light peak, Fig. 2D). This shift is absent in intact nuclei under conditions where replication foci are not formed, that is, in the presence of aphidicolin (Fig. 2A, filled circles) or in the absence of the S-phase extract (Fig. 2B). When sheared genomic DNA is used as template, a very pronounced peak of light-light DNA is formed, but no heavy-light DNA is detected (Fig 2C). These results indicate that neither the heavy-light peak nor the replication foci can be artefactually produced by the high repair activity that produces a peak at the light-light position.

In Xenopus egg extracts, in which the template DNA assembles spontaneously into membrane-bound nuclei, replication depends entirely on the integrity of the nuclear envelope (Blow and Laskey 1986; Leno et al. 1992). Because our yeast nuclear extracts lack a significant lipid fraction and cannot repair or form nuclear membranes de novo, we are able to impair nuclear envelope integrity in vitro and monitor how this influences replication. Isolated nuclei were washed with $0.1 \%$ Triton X-100, a nonionic detergent that disrupts membranes, and were tested for replication and for their ability to exclude large FITC-derivatized dextran molecules $(>150 \mathrm{kD})$. Control nuclei exclude the FITC-dextran and appear as dark spots in the background fluorescence (Fig. 2F), whereas the Triton-washed nuclei become permeable to FITC-dextran, and become uniformly fluorescent (Fig. 2G). In the replication assay Triton-washed nuclei lose $75 \%$ of their heavy-light peak, whereas the lightlight peak extends into a large shoulder of partially replicated DNA (representing $31 \%$ of overall incorporation; Fig. 2E). The focal staining pattern of DIG-dUTP incorporation is also sensitive to pretreatment of the nuclei with detergent (data not shown). In conclusion, an intact nuclear envelope stimulates semiconservative genomic replication, perhaps by preventing loss of a component essential for initiation. Although the gradients shown are inappropriate for the detection of a heavy-heavy peak, we have no indication from others that rereplication occurs (data not shown).

\section{Replicated nuclei are not competent for reinitiation in $S$-phase extracts}

Proper cell-cycle constraints on replication require that nuclei isolated from $G_{1}$-phase cells can be induced to replicate, whereas $G_{2}$ - and $M$-phase nuclei cannot, even in an S-phase cytoplasm (Rao and Johnson 1970). To examine whether our reconstituted system preserves this control, we monitored replication of pre- and post-Sphase nuclei using a $c d c 16-1$ mutant strain (GA-161) synchronized with $\alpha$-factor at permissive temperature $\left(25^{\circ} \mathrm{C}\right)$. From a portion of these cells, late $\mathrm{G}_{1}$-phase nuclei were isolated at permissive temperature (see Materials and Methods), while the rest of the culture was released from $\alpha$-factor and allowed to accumulate in mitosis at $37^{\circ} \mathrm{C}$, in response to the $c d c 16-1$ defect (arrested with short spindles, unseparated chromosomes, and highCdk1 activity; Sikorski et al. 1990). FACs analysis confirmed that these cells have a 2N DNA content /data not shown), and that the nuclei do not undergo rereplication during the arrest, in contrast with an earlier report (Heichman and Roberts 1996). M-phase nuclei were then isolated and tested for replication at permissive temperatures.

Figure 3B shows that $G_{1}$-phase nuclei efficiently incorporate derivatized dUTP in subnuclear foci in wild-type S-phase extracts, whereas $c d c 16$-arrested nuclei fail to incorporate nucleotides (cf. Fig. 3, B and C). Quantitation of DIG-dUTP in $\mathrm{G}_{1}$ - and M-phase nuclei was calculated as the ratio of green to red fluorescent signals (DIGdUTP to DNA, see Materials and Methods) on eight lowmagnification fields of nuclei (Fig. 3D, darkly shaded 
Figure 2. Density substitution of $\mathrm{G}_{1}$ nuclei incubated in yeast nuclear extracts. $(A)$ About $10^{7}$ GA-59 nuclei isolated from cells arrested in $\mathrm{G}_{1}$ with $\alpha$-factor were incubated under standard conditions in a GA-59 S-phase extract with $\left[\alpha{ }^{32} \mathrm{P}\right] \mathrm{dATP}$ and $20 \mu \mathrm{M}$ BrdUTP replacing dTTP (see Materials and Methods) in the presence (O) or absence $(O)$ of aphidicolin. DNA was separated on a $\mathrm{CsCl}$ gradient, the refractory index was measured for each fraction and the incorporated $\left[\alpha-{ }^{32} \mathrm{P}\right] \mathrm{dATP}$ was quantified on a Packard liquid scintillation counter. The peak at fraction 4 corresponds to heavy-light DNA (HL) containing one strand fully substituted with BrdUTP, whereas the peak at fraction 11 corresponds to nonsubstituted DNA (LL). (B) An experiment identical to that in $A$ was performed in a $G_{1}$ nuclear extract, resulting in no heavy-light peak. (C) The same amount of sheared nuclei (genomic DNA/ was incubated in an S-phase extract in the presence of BrdUTP as described in above. A large light-light, but no heavy-light peak is obtained. (D) To monitor the sedimentation of heavy-light DNA, M13mp18 DNA was primed with M13 universal primer and elongated with Sequenase in the presence of dTTP or BrdUTP, and $\left[\alpha-{ }^{32} \mathrm{P}\right] \mathrm{dATP}$. The two reaction products were mixed and and separated on $\mathrm{CsCl}$ gradients (see Materials and Methods). (E) An equal amount of intact $\mathrm{G}_{1}$-phase nuclei (open circles), and the same nuclei washed for $15 \mathrm{~min}$ in $0.1 \%$ Triton X-100 at $4^{\circ} \mathrm{C}$ before the replication reaction (O) were assayed for BrdUTP incorporation under the standard replication conditions. The heavy-light peak is reduced by $75 \%$ by the detergent treatment, whereas a shoulder of par-
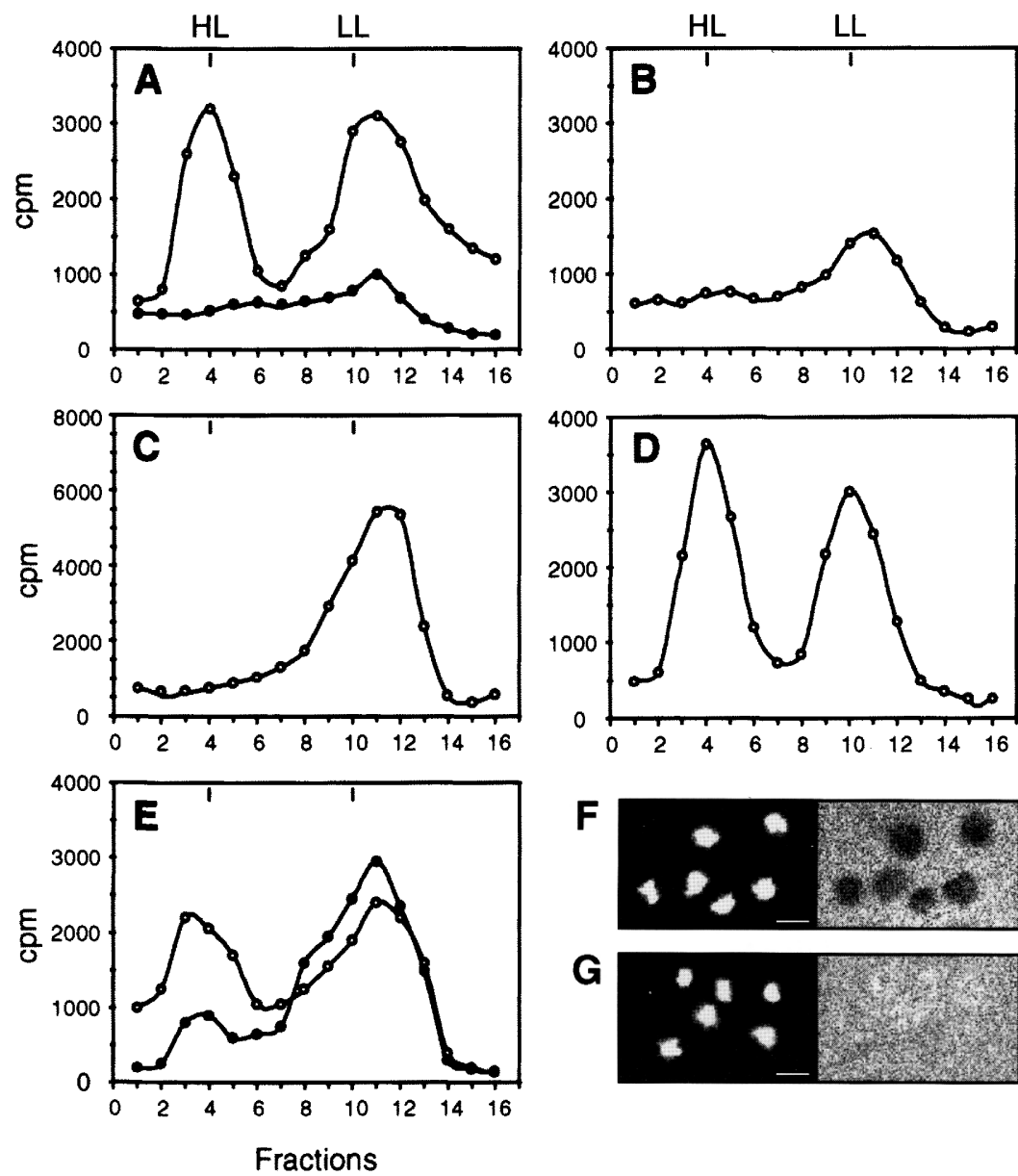

F

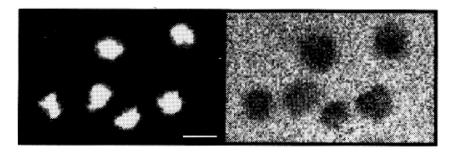

G

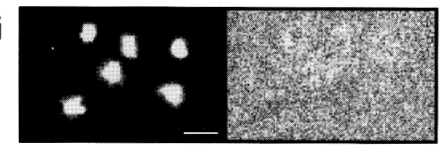
tially replicated DNA is increased by the pretreatment. $(F, G)$ To monitor nuclear membrane integrity, intact nuclei (stained with EtBr in the left panel of $F$ or Triton-washed nuclei (stained with $\mathrm{EtBr}$ in the left panel of $G$ ) were incubated with 150-kD FITC-dextran molecules (see Materials and Methods). Fluorescence images (right panels) show that intact nuclei exclude FITC-dextran (F), whereas Triton-washed nuclei do not $(G)$. Bar, $2 \mu \mathrm{m}$.

bars). In parallel, the fraction of nuclei incorporating label was determined (Fig. 3D, lightly shaded bars). In summary, nuclei isolated from cells arrested in $G_{1}$ replicate efficiently $(65 \%$ of input nuclei contain foci $\mid$, whereas nuclei from metaphase cells do not $(<3 \%)$, suggesting that post-S-phase chromosomes can not rereplicate in our S-phase extracts.

To confirm that the absence of replication in these nuclei represents a postreplicative control, and not an irreversible $c d c 16$-specific defect, nuclei were isolated from cells traversing $G_{2} / M$ synchronously after an $\alpha$-factor block/release step (Fig. 3E, lane 3), from cells arrested in late $\mathrm{G}_{2}$ by either the $c d c 28-1 \mathrm{~N}$ mutation (Fig. 3E, lane 4; Surana et al. 1991) or the addition of nocodazole (Fig. 3E, lane 5). As for cdc16-1 M-phase nuclei (Fig. 3E, lane 6), in all cases the total nucleotide incorporation in these nuclei is $-60 \%$ lower than that in $\mathrm{G}_{1}$ - or $\mathrm{S}$-phase nuclei $(\alpha$-factor block; Fig. 3E, lane 2; or block-release; Fig. 3E, lane 1). When analyzed, the $G_{2} / M$ nuclei also fail to reveal replication foci (e.g., Fig. $3 \mathrm{C}$ ). The difference in nucleotide incorporation between $\mathrm{G}_{1}$ - and M-phase nu- clei is less pronounced when quantified by $\left[\alpha^{32} \mathrm{P}\right] \mathrm{dATP}$ incorporation for the reasons outlined above; the aphidicolin-sensitive background incorporation into sheared DNA is not visualized when replication is scored by DIG-dUTP fluorescence microscopy. In addition to $\mathrm{G}_{2}$ and $\mathrm{M}$-phase nuclei, nuclei isolated from noncycling cells, obtained after a 5-day incubation of cells on glycerol-containing media, also reveal negligible amounts of deoxynucleotide incorporation on introduction into an $S$-phase extract, consistent with the absence of the prereplication complex at ARS1 in these nuclei (Diffley et al. 1994; H. Renauld and P. Pasero, unpubl.).

\section{Initiation of DNA replication occurs in S-phase extracts in vitro}

In the above experiments, $\mathrm{G}_{1}$-phase nuclei were isolated from MATa cells that had been synchronized at Start by the yeast pheromone, $\alpha$-factor. Nuclear isolation requires that the cell wall be degraded by incubation with glycolytic enzymes in an osmotically buffered yeast me- 
A

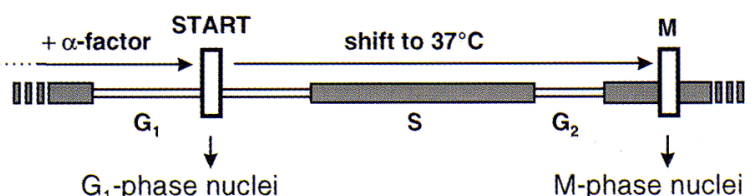

B
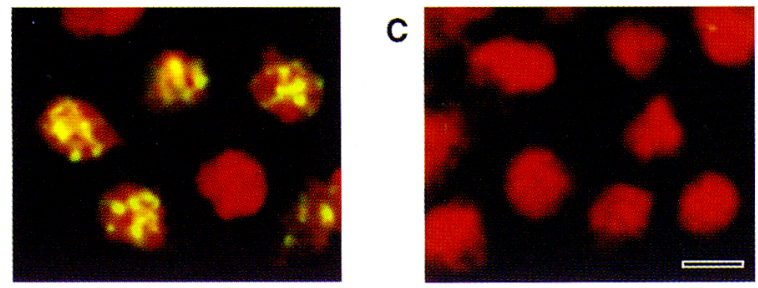

D
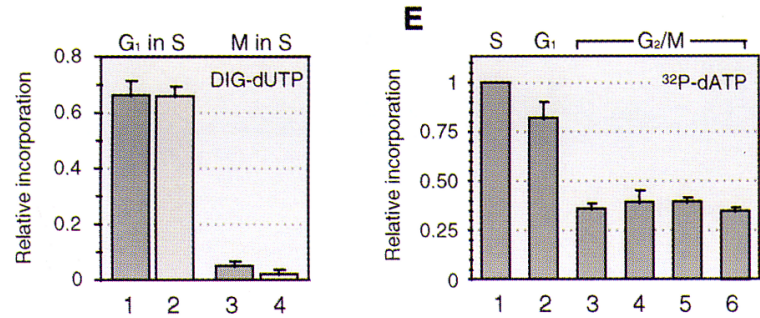

Figure 3. $G_{1}$ nuclei replicate in S-phase extracts, whereas $M$ phase nuclei do not. (A) A schematic representation of the synchronization of cdc16-1 cells is shown. Cells were grown at $25^{\circ} \mathrm{C}$ to $10^{7}$ cells $/ \mathrm{ml}$ and were blocked in $\mathrm{G}_{1}$ phase with $\alpha$-factor. Half of the culture was immediately spheroplasted, whereas the other half was released from the $\alpha$-factor block and shifted for $4 \mathrm{hr}$ at $37^{\circ} \mathrm{C}$ to accumulate in $\mathrm{M}$-phase, from which $\mathrm{G}_{1}$ - and $M$-phase nuclei were isolated identically. $(B)$ About $10^{7} \mathrm{G}_{1}$ nuclei were incubated for $90 \mathrm{~min}$ at $25^{\circ} \mathrm{C}$ in a wild-type S-phase extract in the presence of DIG-dUTP, as described above. Sites of incorporation were detected by anti-DIG-FITC (green), which is superimposed on the EtBr-stained nuclei (red). (C) The same assay was performed at $25^{\circ} \mathrm{C}$ with nuclei from cdc16-1 cells arrested by the shift to $37^{\circ} \mathrm{C}$. Bar, $2 \mu \mathrm{m}$. (D) Quantitation of the DIG-dUTP incorporation in $\mathrm{G}_{1}$ - and $M$-phase nuclei is based on the ratio of green signal (DIG-dUTP) versus red (DNA) on eight low-magnification images (dark labeled bars), and on the ratio of labeled/unlabeled nuclei (lightly shaded bars) determined for a total of 400 nuclei. $(E)$ Identical amounts of nuclei isolated at different points of the cell cycle were assayed for $\left[\alpha{ }^{32} \mathrm{P}\right] \mathrm{dATP}$ incorporation in S-phase extract. (Lane 1) Wild-type S-phase nuclei; (lane 2) wild-type $\mathrm{G}_{1}$ nuclei; (lane 3) wild-type $\mathrm{G}_{2} / \mathrm{M}$ nuclei released from an $\alpha$-factor block; (lane 4) nuclei from $c d c 28-1 \mathrm{~N}$ cells blocked in $\mathrm{G}_{2}$ by a 4 -hr shift at the restrictive temperature; (lane 5) nuclei from wild-type cells blocked in M-phase with nocodazole; (lane 6) nuclei from $c d c 16$ cells blocked at the restrictive temperature. Incorporation of label in genomic DNA was determined by PhosphorImager scanning after separation on a $1 \%$ agarose gel. All values were normalized to the amount of DNA in the sample and incorporation is expressed relative to that of S-phase nuclei incubated in S-phase extracts.

dia for $15 \mathrm{~min}$ at $25^{\circ} \mathrm{C}$. Because $\alpha$-factor and its cellsurface receptor are sensitive to degradation, some cells may progress past Start during this treatment, resulting in an ill-defined population of $\mathrm{G}_{1}$ spheroplasts situated between Start and the beginning of S-phase. We can con- firm that this population has not entered S-phase by following the time-course of bud appearance after $\alpha$-factor arrest, and monitoring the absence of replication intermediates in the endogenous $2 \mu$ circle in the $\alpha$-factortreated spheroplasts (see Fig. 6A-C, below). However, to demonstrate conclusively that our system promotes a $\mathrm{G}_{1} / \mathrm{S}$ transition and the initiation of DNA replication in vitro, we tested template nuclei from two strains that confer a tight genetic block in $G_{1}$ without pheromone treatment.

As outlined in Fig. 4A, cdc7-1 cells were first blocked in $G_{1}$ with $\alpha$-factor and then released from the pheromone block at $37^{\circ} \mathrm{C}$ to allow cells to accumulate at the $\mathrm{G}_{1} / \mathrm{S}$ boundary with maximum synchrony (Brewer and Fangman 1987). Spheroplasting was performed at the restrictive temperature for the $c d c 7-1$ mutation and the absence of replication intermediates in cdc7-arrested spheroplasts was confirmed by two-dimensional gels of the $2 \mu$ circle (Fig. 4B). In a control experiment, the same amount of DNA was extracted from spheroplasts of cells that were released at permissive temperature to enter S-phase. Here abundant replication intermediates are detected in the $2 \mu$ circle (RIs; Fig. 4 C). The nuclei isolated from $c d c 7$ cells arrested at the $G_{1} / S$ boundary were assayed for DNA replication in an S-phase extract in the presence of DIG-dUTP, and we observed the efficient formation of replication foci (Fig. 4D). This indicates that in our in vitro system nuclei can traverse the $G_{1} / S$ boundary and initiate DNA synthesis.

To determine whether nuclei arrested earlier in $G_{1}$ can also initiate DNA replication, we have used a strain triply deleted for the $\mathrm{G}_{1}$ cyclins, bearing a copy of $C L N 3$ under the control of a galactose-inducible promoter. Because progression past Start requires induction of a repressed promoter and synthesis of $C \ln 3 p$, this strain is tightly arrested at the restriction point, or Start, in the presence of glucose or raffinose (Cross 1990; summarized in Fig. 4E). Cells were grown on YP/Gal (see Materials and Methods) to log phase, and were arrested at Start by replacing galactose with glucose. After arrest, these cells were spheroplasted in the presence of glucose, maintaining the Start-I arrest (Fig. 4E). In a parallel population, $c l n^{-}$cells were blocked at Start with raffinose, and then released by the addition of galactose, to allow synchronous cell-cycle progression, and isolation of S-phase nuclei. We observed that both $c \ln ^{-}$-arrested $\mathrm{G}_{1}$-phase nuclei and the released, S-phase nuclei replicate efficiently in vitro and form replication foci in S-phase extracts (Fig. $4 F, G$ ). Both the efficient formation of replication foci (insets in Fig. 4, F and $G$, and lightly shaded bars in $H$ ) and the elevated incorporation of DIG-dUTP (Fig. 4H, darkly shaded bars) require the addition of S-phase nuclear extract (see insets in Fig. 4F,G).

The quantitation of DNA synthesized shows that the level of DNA synthesis in cln-deficient nuclei is comparable with that observed in $\alpha$-factor-arrested nuclei (Fig. $4 \mathrm{I}$; Table 1), whereas in the absence of S-phase extract, the $\left[\alpha-{ }^{32} \mathrm{P}\right] \mathrm{dATP}$ incorporation in $\mathrm{G}_{1}$ nuclei is reduced to the level of background synthesis in $G_{2}$ - or $M$-phase nuclei (data not shown). We observe no significant lag pe- 
Figure 4. Nuclei prepared from cells blocked in late $\mathrm{G}_{1}$-phase with the $c d c 7$ mutation or in the absence of cyclins are able to initiate DNA replication in an S-phase extract. $(A)$ cdc7-1 cells were arrested in late $G_{1}$ using the double block procedure described by Brewer and Fangman (1987). Half of the culture was immediately spheroplasted at $37^{\circ} \mathrm{C}$ for late $G_{1}$-phase nuclei, whereas the rest of the cells were released into $S$-phase before spheroplasting. $(B)$ Two-dimensional gel analysis of the $2 \mu$ circle from spheroplasts blocked at the $C D C 7$ execution point. Electrophoresis, transfer, and hybridization were carried out as described in Materials and Methods after digestion of genomic DNA with ApaI. (C) Two-dimensional gel analysis of the $2 \mu$ circle from spheroplasts in S-phase. The arrowhead points to the replication intermediates. $(D) \mathrm{Cdc} 7$ arrested nuclei were incubated in an wild-type S-phase extract at $23^{\circ} \mathrm{C}$, and DIG-dUTP incorporation (green) is superimposed on the DNA stain (red). Bar, 1 um. (E) K3130 cells (cIn1::hisG, cln2::del, cln3::GAL::CLN3) were grown on YP/ Raff $/ \mathrm{Gal}$ to the density of $10^{7} / \mathrm{ml}$ and were blocked in $G_{1}$ either by transferring the culture to YP/Glu or to YP/Raff until all the cells presented the dumbbell phenotype. Cells blocked on YP/Glu were spheroplasted in the presence of glucose to prepare $G_{1}$ nuclei, whereas cells blocked on YP/Raff were released into S-phase with the addition of $2 \%$ galactose and were spheroplasted when $>80 \%$ of the cells showed small buds. $\mathrm{K} 3130 \mathrm{G}_{1}$-phase $(F)$ and S-phase $(G)$ nuclei were assayed for in vitro DNA replication 190 $\min , 25^{\circ} \mathrm{C}$ ) in a wild-type S-phase extract in the presence of DIG-dUTP, which is detected as described above. The insets show a low magnification image of identical nuclei incubated in the absence of the S-phase extract. $(H)$ The incorporation of DIG-dUTP in $\mathrm{G}_{1}$ (lanes 1,2) or S-phase nuclei (lanes 3,4) in the presence (lanes 1,3 ) or the absence (lanes 2,4) of S-phase extract was performed as described above. Darkly shaded bars indicate the ratio of FITC::EtBr, whereas lightly shaded bars show the fraction of nuclei containing replication foci. (I) Time-course of total DNA synthesis determined by incorporation of $\left[\alpha-{ }^{32} \mathrm{P}\right] \mathrm{dATP}$ in $\mathrm{G}_{1}$ - and S-phase nuclei incubated under standard conditions in a wild-type S-phase extract.
A

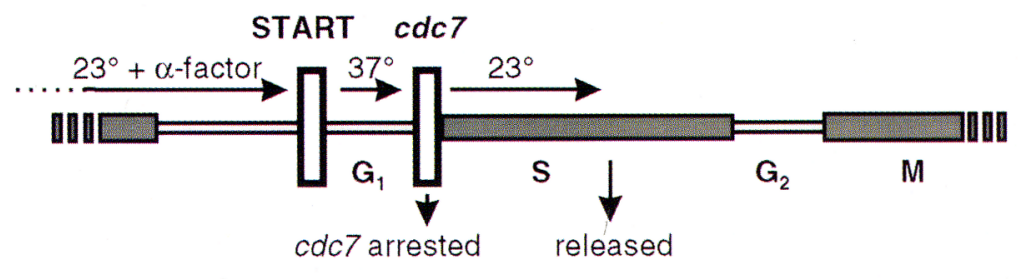

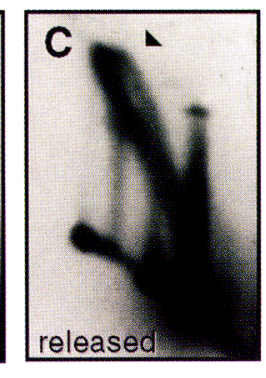

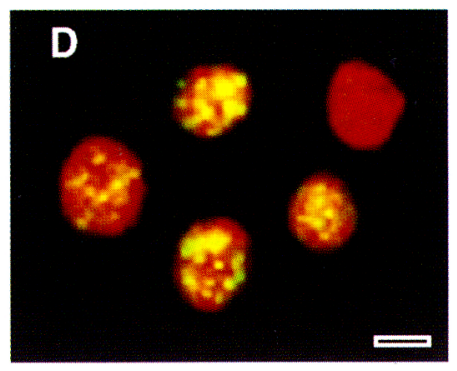

$E$
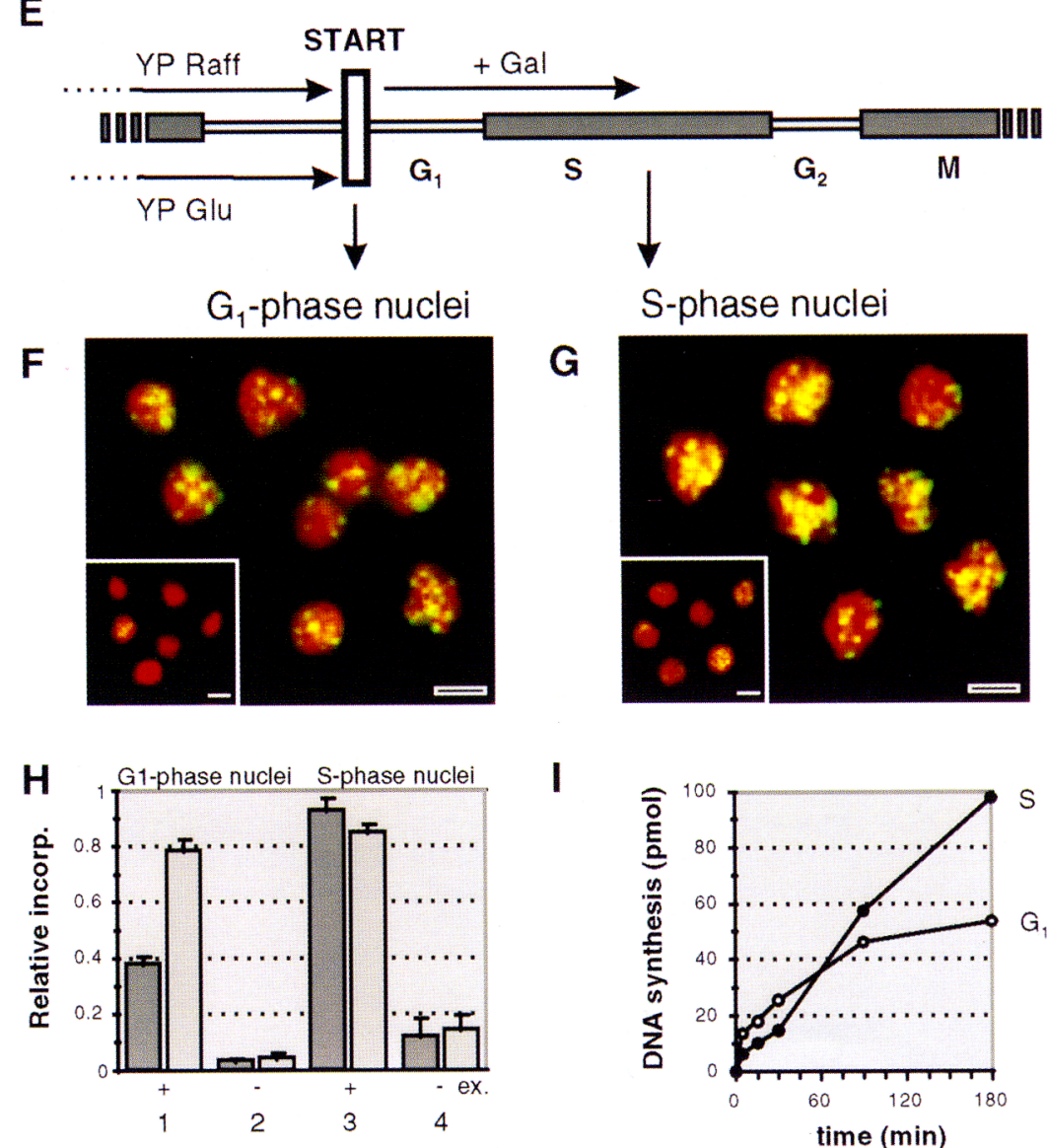

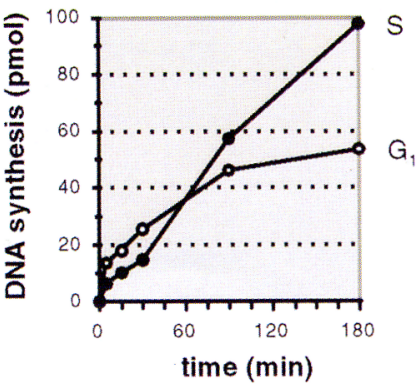

riod for the incorporation of $\left[\alpha^{-32} \mathrm{P}\right] \mathrm{dATP}$ in $\mathrm{G}_{1}$ nuclei (Fig. 4I), but because this incorporation represents both repair and semiconservative DNA replication, we assume that a lag time would be masked by the repair activity, which is very high during the first minutes of the reaction (P. Pasero, unpubl.).
Elongation of engaged polymerases in the absence of extract is inefficient

When S-phase nuclei are incubated with nucleotides and the ATP-regenerating system, but without the S-phase extract (Fig. 4, G, inset, and $H$, lane 4), we detect a fairly 
low level of incorporated DIG-dUTP, which is roughly five times the background level in $\mathrm{G}_{1}$-phase nuclei without extract (Fig. 4, F, inset, and $\mathrm{H}$, lane 2). Moreover, although the proportion of nuclei that have foci is roughly the same for $\mathrm{G}_{1}$ - and S-phase nuclei in the presence of S-phase extract (Fig. 4F-H), the net incorporation measured by either the dUTP::DNA ratio (darkly shaded bars, Fig. $4 \mathrm{H}$ ), or by $\left[\alpha{ }^{32} \mathrm{P}\right]$ dATP incorporation (Fig. $\left.4 \mathrm{I}\right)$, is higher in the S-phase nuclei after a 3-hr incubation. Because much of the nucleotide incorporation in S-phase nuclei is likely to be attributable to DNA synthesis by engaged polymerases (elongation), it appears that, in addition to initiation, the elongation rates and/or extent of replication are stimulated by S-phase factors. We can rule out that the extracts themselves nick or partially degrade DNA to stimulate nonreplicative DNA synthesis, because supercoiled, open circular and linear DNAs are stable in S-phase extracts for at least $180 \mathrm{~min}$ at $30^{\circ} \mathrm{C}$ (D. Braguglia, P. Pasero, B. Duncker, P. Heus, and S. Gasser, in prep.).

\section{A 6-DMAP-sensitive component is supplied by the S-phase extract}

The induction of replication in $\mathrm{G}_{1}$-phase nuclei is entirely dependent on a protein component of the S-phase extract, because heat-denaturation of its proteins (Fig. $5 \mathrm{~A}$, lane 4), or substitution with a $\mathrm{G}_{1}$-phase extract (Fig. $5 \mathrm{~A}$, lane 3 ) reduces semiconservative DNA replication by $>75 \%$, as judged by integration of the heavy-light peaks after density gradient sedimentation. Similarly, omission of the extract eliminates the appearance of replication foci (Figs. 4F and 5B, lane 4). We also present evidence that the initiation-promoting factor in the extract is sensitive to 6-dimethylaminopurine (6-DMAP), a purine analog that inhibits a variety of protein kinases, including cdc2-like kinases (Meijer and Pondaven 1988). Incubation of the S-phase extract with 6-DMAP, reduces the DIG-dUTP incorporation in $\mathrm{G}_{1}$-phase nuclei by 3.5fold (Fig. 5B, lane 2). This is consistent with its ability to inhibit the initiation, but not elongation, of DNA replication in Xenopus egg extracts (Blow 1993).

The initiation-stimulating activity of the extract does not depend on an active pol $\alpha$-primase complex, because an extract prepared from the pri1-1 strain, which is temperature sensitive for pol $\alpha$-primase activity (Francesconi et al. 1991) promotes replication in $\mathrm{G}_{1}$-phase nuclei at both permissive $\left(25^{\circ} \mathrm{C}\right)$ and restrictive $\left(37^{\circ} \mathrm{C}\right)$ temperatures, at levels comparable with wild-type extracts (Fig. $5 \mathrm{C}$, lanes 1,2 ; E, darkly shaded bars). The temperaturesensitivity of the primase activity in these extracts is confirmed by the fact that both label incorporation (Fig. $5 \mathrm{D}$, lanes 1,$2 ; \mathrm{E}$, lightly shaded bars) and the appearance of replication intermediates in supercoiled plasmid, drop significantly at restrictive temperature, which is not the case in wild-type nuclear extracts (D. Braguglia, P. Pasero, B. Duncker, P. Heus, and S. Gasser, in prep.).

\section{DNA synthesis initiates at replication origins in isolated yeast nuclei}

Is initiation origin-specific in vitro? The neutral/neutral two-dimensional gel technique of Brewer and Fangman (1987) enables us to analyze initiation on multicopy plasmids carried by the isolated nuclei. We first examine
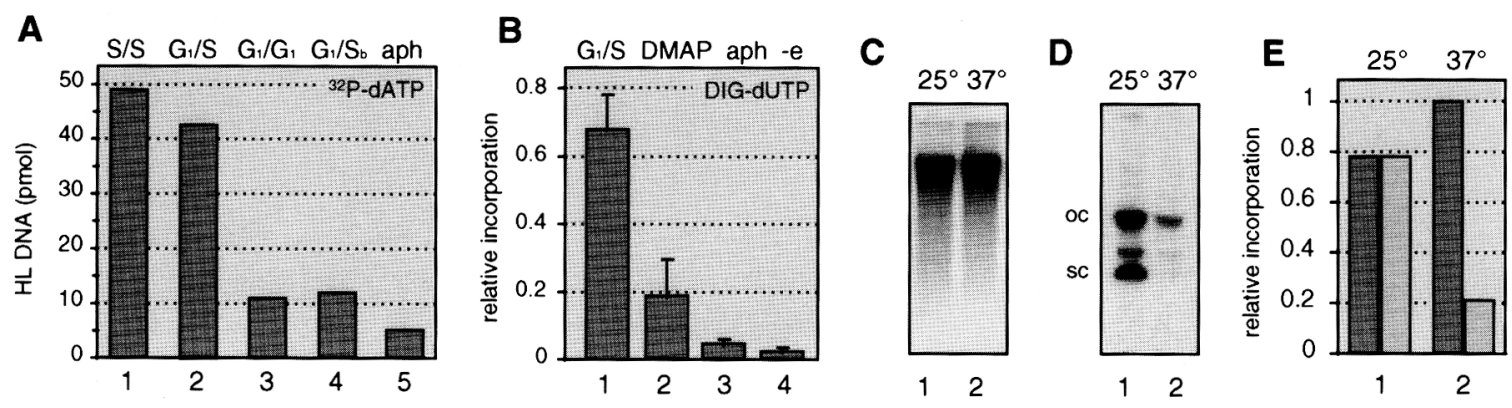

Figure 5. The S-phase nuclear extract provides a 6-DMAP sensitive component necessary for the initiation of DNA replication in isolated $G_{1}$ nuclei. $(A)$ Nuclei were isolated from GA-59 cells arrested in $G_{1}$ by afactor, or released into $S$ phase, and were incubated in wild-type $S$-phase extracts as described above. Semi-conservative DNA replication was quantitated after a 3-hr reaction by integrating the heavy-light peak of each gradient, as described in Materials and Methods. (1) S-phase nuclei in $S$ extract; (lane 2) $\mathrm{G}_{1}-$ phase nuclei in $S$ extract; (lane 3) $G_{1}$ nuclei in $G_{1}$ extract; (lane 4) $G_{1}$ nuclei in $S$ extract inactivated by heating $\left(5\right.$ min at $\left.90^{\circ} \mathrm{C}\right)$; (lane 5$)$ $\mathrm{G}_{1}$-phase nuclei in $\mathrm{S}$ extract in the presence of $0.5 \mathrm{mg} / \mathrm{ml}$ of aphidicolin. $(B)$ Similar reactions were performed with wild-type $\mathrm{G}_{1}$ nuclei in wild-type $S$ extracts, incorporating DIG-dUTP, which was quantified as the ratio of green signal versus red on confocal images as described in Fig. 1. (Lane 1) standard reaction, $G_{1}$ nuclei in S-phase extract; (lane 2) as lane 1 with 5 mM 6-DMAP; (lane 3) as lane 1 with $0.5 \mathrm{mg} / \mathrm{ml}$ of aphidicolin; (lane 4) $\mathrm{G}_{1}$ nuclei in the absence of $S$ extract but with NTPs, buffer, and energy regeneration system. $(C)$ About $10^{7}$ GA-59 $\mathrm{G}_{1}$-phase nuclei or $(D) 300 \mathrm{ng}$ of the plasmid pH4ARS (see D. Braguglia, P. Pasero, B. Duncker, P. Heus, and S. Gasser, in prep.) were incubated for $90 \mathrm{~min}$ in a pri1-1 S-phase extract with $\left[\alpha^{-3} \mathrm{P}\right] \mathrm{dATP}$ at either permissive $\left(25^{\circ} \mathrm{C}\right)$ or restrictive temperature $\left(37^{\circ} \mathrm{C}\right)$. pri1-1 is temperature sensitive for the $48-\mathrm{kD}$ subunit of the pol $\alpha$-primase complex (Francesconi et al. 1991). DNA was extracted, separated on a $1 \%$ agarose gel and an autoradiograph is shown. $(E)\left[\alpha-{ }^{32} \mathrm{P}\right] \mathrm{dATP}$ incorporation in genomic DNA (dark shading, $C$ ) and plasmid DNA (light shading, $D$ ) was quantified and normalized relative to the maximal incorporation. Lanes 1 and 2 indicate incubation at permissive $\left(25^{\circ} \mathrm{C}\right)$ or restrictive $\left(37^{\circ} \mathrm{C}\right)$ temperature, respectively. 
initiation at the ARS of the endogenous $2 \mu$ circle in nuclei from $\alpha$-factor-arrested cells, and later extend the analysis to a replicating plasmid in nuclei of a $c d c 7$-arrested culture, as detection of a single-copy origin would require $20-40 \times$ more nuclei than that used in a standard reaction.

Initiation in the $2 \mu$ circle is a sensitive marker for entry into S-phase: Its origin fires early (10 min after release from a cdc7 block; Brewer and Fangman 1987), intermediates remain detectable into mid-S-phase, and both the regulation and chromatin structure reflect that of chromosomal origins (see Diffley et al. 1994). To rule out that cells escape the $\alpha$-factor block during spheroplasting, we looked for the presence of $2 \mu$ plasmid replication intermediates by two-dimensional gel analysis in spheroplasts formed after the standard $\alpha$-factor block $(<5 \%$ buds; Fig. 6B, labeled as 2 ). No replicative forms were detected (Fig. 6C, labeled 2). In contrast, replication intermediates are abundant in spheroplasts from cells with a high budding index (Fig. 6B,C, labeled 3), and are detectable in those from a random population of cells (Fig. 6B,C, labeled 1) in which $<15 \%$ of cells are in early $\mathrm{S}$-phase. The complex pattern of replication intermediates observed at the $2 \mu$ plasmid in vivo reflects originspecific initiation within two recombination isomers (forms A and B, in Fig. 6D). We observe some breakage of the bubble arc during DNA isolation, enhancing the Yarcs. A very similar pattern, consistent with initiation from the $2 \mu$ origin, is observed when $G_{1}$ nuclei, isolated from the spheroplasts shown in Figure 6C, panel 2, are incubated in S-phase extracts (Fig. 6E).

The centered bubble arc characteristic of localized initiation (arc B, Fig. 6D), is more readily seen in a plasmid that does not recombine like the $2 \mu$ circle. To this end,
Figure 6. DNA replication initiates at ARS elements in isolated yeast nuclei. $|A|$ The scheme for the synchronization of GA-462 cells is shown. After growth at $23^{\circ} \mathrm{C}$ cells were incubated for $120 \mathrm{~min}$ in the presence of $\alpha$-factor. Half of the culture was spheroplasted immediately $\left(\mathrm{G}_{1}\right.$-phase $)$, whereas half was released into $S$-phase to follow the reappearance of the buds. $(B)$ Budding index of the cells during the $\alpha$-factor block-release procedure. (C) Two-dimensional gel analysis of the $2 \mu$ circle in spheroplasts prepared at the indicated stages of the $\alpha$-factor blockrelease procedure. Arrowheads point to replication intermediates present in nonsynchronized spheroplasts (1), S-phase spheroplasts (3), but not in spheroplasts from $\alpha$-factor blocked cells $(2)$. (D) Schematic representation of the two isoforms of the $2 \mu$ circle and the pattern obtained on two-dimensional gel after digestion with ApaI. The forms A and B give, respectively, rise to the double-Y arc (dark shading) and to the bubble arc (light shading). (E) Two-dimensional gel analysis of the endogenous $2 \mu$ circle in nuclei prepared from $\alpha$-factor blocked spheroplasts $(C, 2)$ incubated in an S-phase extract. The replication assay was performed as described in Materials and Methods and aliquots corresponding to incubation times of 15,20 , 25 , and $30 \mathrm{~min}$ were pooled. Electrophoresis and detection of the replication intermediates are described above (Fig. 4) after digestion with ApaI. The arrowhead indicates the bubble arc in the B form of the $2 \mu$ circle. Breakage of the bubble arc during isolation enhances the single- $Y$ arc here and in $H .(F) \mathrm{G}_{1}$ nuclei prepared from GA-59 cells transformed with the multicopy plasmid pRS424 were assayed for in vitro replication in an S-phase extract. Two-dimensional gel analysis of pRS424 was performed before the reaction $(G)$ and after the reaction $(H)$. Aliquots corresponding to incubation times of $15,20,25$, and 30 min were pooled, genomic DNA was extracted and digested with EcoRI, which cuts opposite the ARS element, and visualied by two-dimensional gel electrophoresis and Southern hybridization with the backbone of pRS424. Arrowhead points to the bubble arc, indicative of initiation at the replication origin.
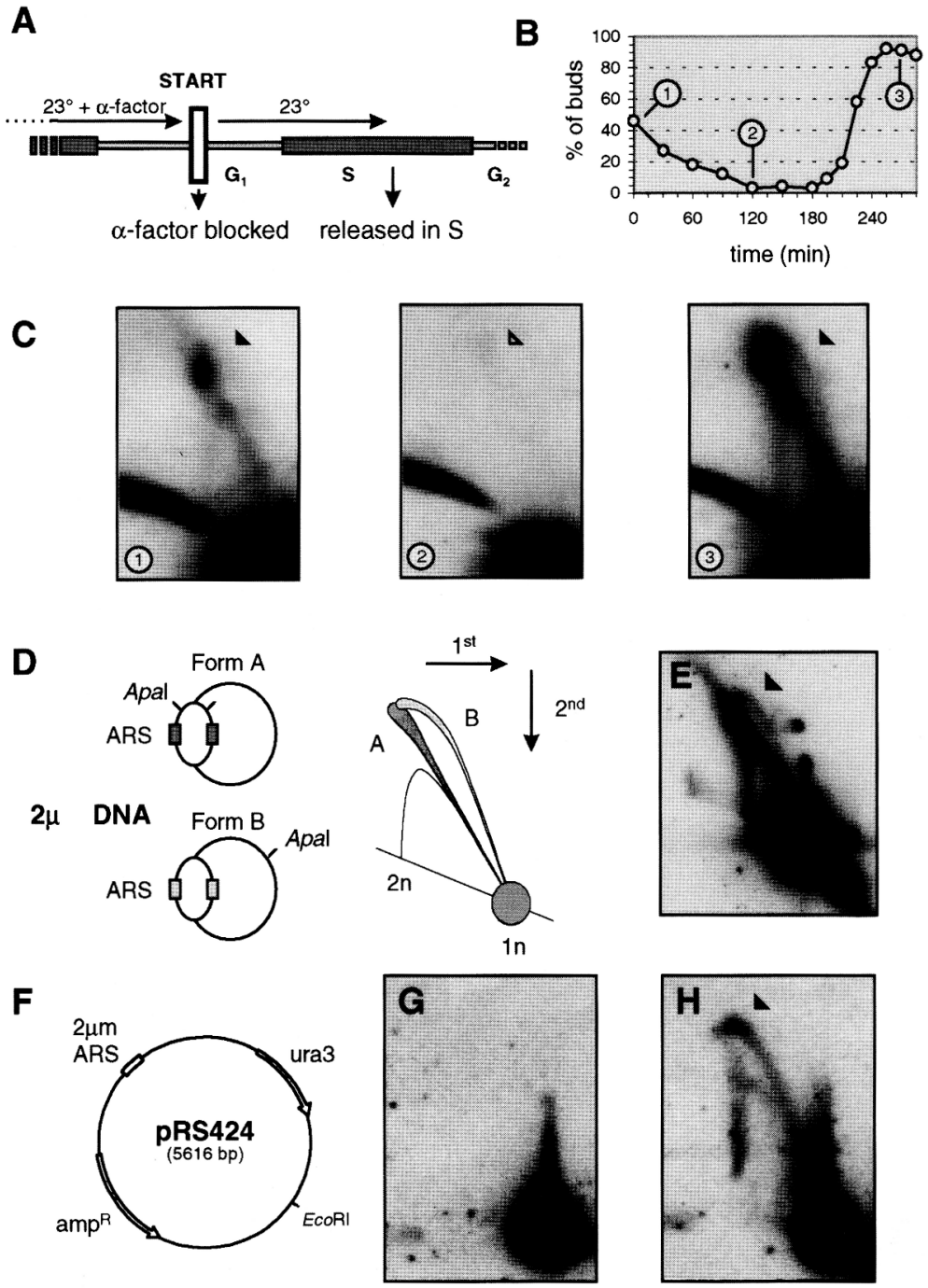
we transformed $c d c 7$ cells with pRS424, a multicopy plasmid bearing the $2 \mu$ ARS (Fig. $6 \mathrm{~F}$ ), and prepared nuclei from $c d c 7$-arrested cells as described above. After incubation in an S-phase extract, digestion with EcoRI, and a two-dimensional/Southern analysis of the pRS424, we observe a strong and complete bubble arc (arrowhead in Fig. $6 \mathrm{H}$ ) indicating that most DNA synthesis initiates at the ARS element in vitro and proceeds bidirectionally from the origin, as it does in vivo (Fig. $6 \mathrm{H}$ ). Moreover, no aberrant recombination or termination intermediates are detected on these two-dimensional gels /see Levac and Moss 1996), suggesting that the termination of DNA replication occurs normally on nuclear minichromosomes in vitro. Because we can detect no replication intermediates in the pRS424 plasmid in $\mathrm{G}_{1}$ nuclei before incubation in the S-phase extract (Fig. 6G), we conclude that replication initiates at the origin during incubation in vitro.

Replication of yeast nuclei in vitro is ORC-dependent

A tight $\mathrm{G}_{1} / \mathrm{S}$ block to replication has never been shown for temperature-sensitive mutations in budding yeast ORC subunits, although it is expected that ORC is essential for the initiation event (Bell et al. 1993; Micklem et al. 1993; Liang et al. 1995). Our in vitro assay allows us to examine whether ORC is required for initiation itself, or for the establishment of an initiation-competent complex, within which it is no longer essential. To test this, orc 2-1 mutant cells were grown and synchronized in $\mathrm{G}_{1}$ by $\alpha$-factor arrest at permissive temperature, and both $\mathrm{G}_{1}$-phase nuclei and S-phase nuclear extracts were prepared from cells synchronized as described in Figure 6A.

The incubation of the $\mathrm{G}_{1}$-phase orc2-1 nuclei in orc2-1 S-phase extracts at permissive temperature reveals the incorporation of DIG-dUTP in well-defined foci in most of the nuclei (Fig. $7 \mathrm{C}$, orc2/orc2 $23^{\circ} \mathrm{C}$ ). Quantitation of these results gives a fluorescein::EtBr ratio of 0.7 , with over $65 \%$ of the nuclei containing replication foci (Fig. $7 \mathrm{D}$, lane 1). At restrictive temperature, in the same extracts and nuclei, foci are observed in less than $10 \%$ of the cells (Fig. $7 \mathrm{C}$, orc $2 /$ orc $237^{\circ} \mathrm{C}$ ), indicating that inactivation of Orc2p in late $G_{1}$ nuclei results in a sixfold drop in both overall DIG-dUTP incorporation and in the
A

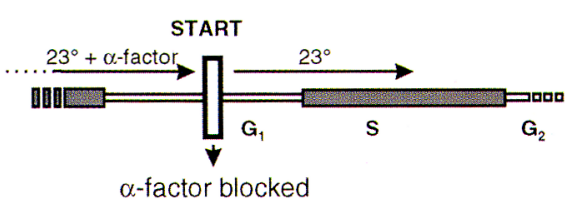

C

$23^{\circ} \mathrm{C}$

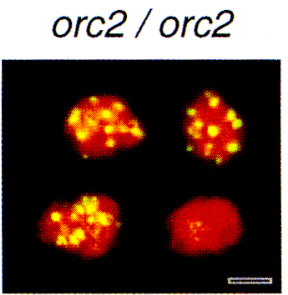

$37^{\circ} \mathrm{C}$

wt / orc2
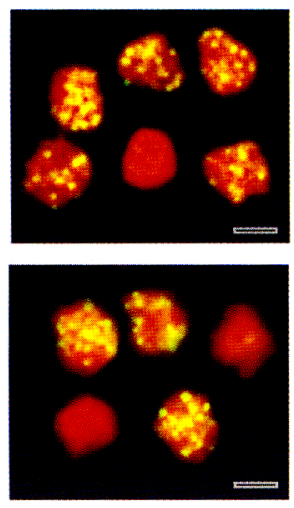

D

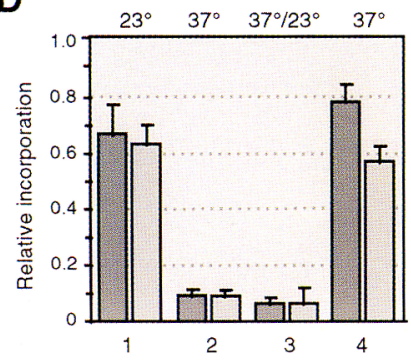

$\mathbf{E}$

B

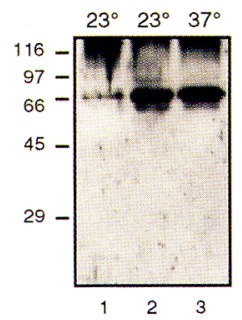

orc2 / wt
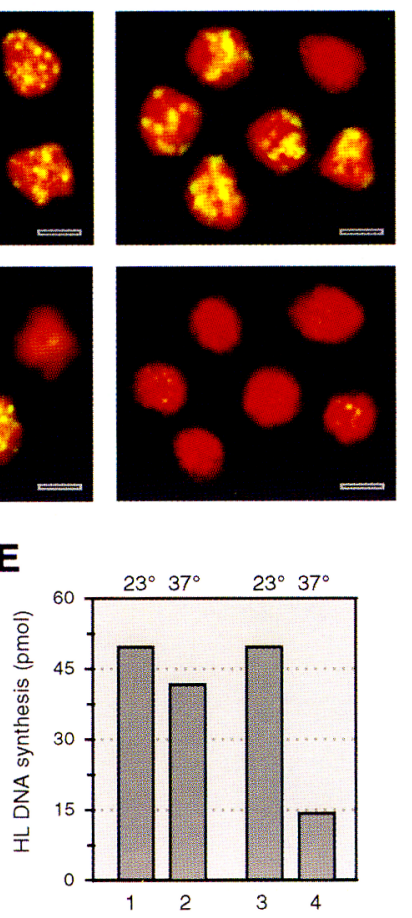

Figure 7. Initiation of DNA replication is ORCdependent in vitro. (A) The synchronization in $\mathrm{G}_{1}$ of orc2-1 cells is for $120 \mathrm{~min}$ in the presence of $\alpha$-factor at $23^{\circ} \mathrm{C}$. (B) Proteins from a total yeast extract (GA-59; lane 1) or from orc2-1 nuclei after incubation for $45 \mathrm{~min}$ at permissive $\left(23^{\circ} \mathrm{C}\right.$, lane 2) or restrictive $\left(37^{\circ} \mathrm{C}\right.$, lane 3$)$ temperature were denatured and probed by Western blot using an antiOrc2p antibody (gift of J. Diffley, Imperial Cancer Research Fund, Herts, UK) to show the absence of degradation of the ORC2 protein. $(C)$ Nuclei isolated from orc2-1 or wild-type (wt) cells synchronized in $G_{1}$ were assayed for in vitro DNA replication in an orc2-1 or a wild-type S-phase extract for $90 \mathrm{~min}$ at $23^{\circ} \mathrm{C}$ or $37^{\circ} \mathrm{C}$ in the presence of DIGdUTP. (orc2/orc2) orc2 nuclei in orc2 extract. (wt/ orc2) Wild-type nuclei in orc2 extract. (orc2/wt) orc2 nuclei in wild-type extract. DIG-dUTP (green) and EtBr (red) staining are as described above. Bar, $1 \mu \mathrm{m}$. (D) Quantitative analysis of DIG-dUTP incorporation in orc2-1 $\mathrm{G}_{1}$ nuclei incubated for $90 \mathrm{~min}$ at $23^{\circ} \mathrm{C}$ in an orc2-1 S-phase extract (lane 1); for $90 \mathrm{~min}$ at $37^{\circ} \mathrm{C}$ in an orc2-1 Sphase extract (lane 2); in an orc2-1 S-phase extract for $15 \mathrm{~min}$ at $37^{\circ} \mathrm{C}$ (lane 3 ), then $75 \mathrm{~min}$ at $23^{\circ} \mathrm{C}$ with DIG-dUTP. (Lane 4) Wild-type nuclei incubated for $90 \mathrm{~min}$ at $37^{\circ} \mathrm{C}$ in an orc2-1 S-phase extract. The incorporation of DIG-dUTP /dark gray bars) and the proportion of replicating nuclei (light gray bars) were determined as indicated in Materials and Methods. $(E)$ Quantitation of semiconservative replication in $10^{7}$ wild-type (lanes 1,2$)$ and orc2 nuclei (lanes 3,4 ) incubated for $3 \mathrm{hr}$ in an orc2 extract at $23^{\circ} \mathrm{C}$ (lanes 1,3 ) or $37^{\circ} \mathrm{C}$ (lanes 2,4$)$. The reaction and separation on $\mathrm{CsCl}$ gradients were performed as described in Materials and Methods. The moles of semiconservatively synthesized DNA was calculated from the $\left[\alpha{ }^{32} \mathrm{P}\right] \mathrm{dATP}$ recovered in the heavy-light peak. 
number of nuclei containing replication foci (Fig. 7D, lane 2). We show next that a shift of the isolated $\mathrm{G}_{1}$ phase orc2-1 nuclei to $37^{\circ} \mathrm{C}$ for as little as $15 \mathrm{~min}$, followed by a return to permissive temperature, is sufficient to eliminate the appearance of replication foci (quantitation in Fig. 7D, lane 3), although wild-type nuclei replicate efficiently in orc2 S-phase extracts even when incubated continuously at $37^{\circ} \mathrm{C}$ (Fig. $7 \mathrm{C}$, wt/orc2; and $D$, lane 4). The lack of replication in $\mathrm{G}_{1}$ orc2-1 nuclei at restrictive temperature was confirmed by BrdUTP substitution and quantitation of the heavy-light peak on $\mathrm{CsCl}$ gradients (Fig. 7E, cf. lane 2, wild type, with lane 4, orc2-1). This confirms that foci are not simply disorganized at restrictive temperature, but that replication itself is blocked. Western blots for Orc2p on a whole-cell extract of GA-59 cells (wild type, Fig. 7B, lane 1) and on equal amounts of protein from orc2-1 nuclei incubated at either $23^{\circ} \mathrm{C}$ or $37^{\circ} \mathrm{C}$ (Fig. $7 \mathrm{~B}$, lanes 2 and 3 ), rule out that Orc2p is degraded at $37^{\circ} \mathrm{C}$ in the temperature-sensitive strain. Orc $2 p$ is also readily detectable on Western blots of both wild-type and orc2 S-phase extracts prepared at permissive temperature.

\section{ORC-deficient nuclei are not complemented by wild-type extracts}

If ORC also serves an essential role in $G_{1}$-phase for establishing a replication competent origin complex, we predict that the orc2-1 deficiency cannot be complemented by ORC components found in a wild-type S-phase extract. To test this, orc2-1 $\mathrm{G}_{1}$-phase nuclei were incubated in wild-type S-phase extracts at either $23^{\circ} \mathrm{C}$ or $37^{\circ} \mathrm{C}$, and replication was monitored by both isotope incorporation and the appearance of DIG-dUTPcontaining foci. As observed in the orc2-1 extracts, the replication foci appear normal at permissive temperature, but little nucleotide is incorporated at $37^{\circ} \mathrm{C}$ (Fig. $7 \mathrm{C}$. On the other hand, wild-type nuclei incubated in an orc2-1 extract incorporate DIG-dUTP with high efficiency at both permissive and restrictive temperatures (Fig. $7 \mathrm{C}$ ), in an aphidicolin-sensitive manner (data not shown). Therefore, the orc2-1 deficiency is manifest in the substrate nuclei, and cannot be complemented in trans with the wild-type ORC present in S-phase extracts.

\section{Discussion}

We have established a reliable DNA replication system from yeast supporting efficient semiconservative DNA synthesis in vitro. This replication is sensitive to the cell-cycle controls that ensure that the genome is replicated once and only once per cell cycle, because neither $\mathrm{G}_{2^{-}}, \mathrm{M}$-, nor noncycling $\mathrm{G}_{0}$-phase nuclei replicate in the S-phase extract. Moreover, replication initiates in an origin-specific and ORC-dependent fashion in vitro. The application of this assay to the many cell cycle- and DNA replication-specific mutants in yeast should allow a detailed biochemical characterization of the $G_{1}$-to-S phase transition and its relation to the initiation of DNA replication.

\section{Replication occurs in distinct foci within yeast nuclei}

A large fraction of the DNA synthesis that we observe in vitro is semiconservative as judged by density substitution (Fig. 2). Quantitation of incorporated nucleotides indicates that between 20 and 30 ng of DNA is synthesized in the 90 -min reaction representing $20 \%-30 \%$ of the input DNA (Table 1). These values include both replicative and nonreplicative events within high-molecular-weight DNA. To avoid any signal from the repair of damage in contaminating free DNA, we visualize DNA replication through the incorporation of derivatized deoxynucleotides into the chromosomes of intact nuclei, and follow the appearance of foci by confocal microscopy (Fig. 1). We show that yeast nuclear replication, like that of vertebrate nuclei (Nakamura et al. 1986), occurs at distinct subnuclear foci containing clusters of replication forks, and that their appearance correlates with the recovery of a heavy-light peak on density gradient centrifugation. The incorporation detected in this manner can be quantified in a relative fashion, as units of nucleotide-bound fluorescence relative to the $\mathrm{EtBr}$ signal of the entire genome. Calculating the number of replicating nuclei in a given population indicates that $60 \%-70 \%$ of the nuclei isolated from either $\mathrm{G}_{1}$ - or S-phase spheroplasts, replicate in an S-phase extract, indicating a high efficiency of in vitro initiation.

\section{Initiation in vitro is origin specific and ORC-dependent}

Origins of replication are well characterized in yeast (for review, see Campbell and Newlon 1991). This has allowed us to demonstrate that the initiation of replication in vitro is origin-specific, by mapping bubble arcs on both multicopy plasmids and the endogenous $2 \mu$ circle (Fig. 6). This initiation activity is compromised at restrictive temperature in the conditional orc $2-1$ mutant (Fig. 7). In contrast, we observed that initiation on supercoiled plasmids introduced into these same S-phase extracts occurred randomly and in an ARS- and ORC-independent manner (D. Braguglia, P. Pasero, B. Duncker, P. Heus, and S. Gasser, in prep.; data not shown). This suggests either that subnuclear organization aids in origin function, or that the necessary preinitiation complexes cannot form on plasmid DNA in S-phase extracts. This is consistent with observations in the Xenopus system, where replication of naked DNA occurs with little or no sequence specificity (Hyrien and Méchali 1992; Gilbert et al. 1995), whereas "preorganized" Chinese hamster ovary $(\mathrm{CHO})$ cell nuclei introduced into Xenopus extracts initiate preferentially at a putative dihydrofolate reductase (DHFR) origin (Gilbert et al. 1995; Wu and Gilbert 1996).

Interestingly, ORC has an essential role in the de novo formation of replication centers in Xenopus egg extracts, although this organization does not fully mimic that in 
somatic cells. Orc2p associates with chromatin in the first stages of nuclear formation in egg extracts (Carpenter et al. 1996), and is thought to be required for the recruitment of Cdc6p and MCMs, both essential for initiation of DNA replication in vitro (Coleman et al. 1996; Romanowski et al. 1996). Elsewhere we show that ORC and Cdc6p are associated with an insoluble nuclear scaffold fraction in $\mathrm{G}_{1}$ - and S-phase yeast nuclei (P. Pasero and S.M. Gasser, in prep.|, consistent with a role for ORC in the formation of replication centers. The inactivation of preformed replication complexes by a shift to restrictive temperature in orc2-1 nuclei, indicates that ORC is not only required for the assembly step, but also for initiation itself.

\section{Cis- and trans-acting factors are required for the initiation of DNA replication in vitro}

The "licensing factor" model, essentially based on observations in the Xenopus system, proposes that replication competence is attributable to the presence of a positive factor bound to chromatin in $G_{1}$, which is essential for the initiation of replication. The factors are subsequently inactivated during replication and remain inactive until the transit of mitosis (Blow and Laskey 1988). Several reviews have pointed out that this licensing event in budding yeast could reflect the association of Cdc6p, Dbf4p, or MCM proteins to the origin-bound ORC, which can occur only after anaphase (for review, see Muzi-Falconi et al. 1996; Donovan and Diffley 1996; Kearsey et al. 1996). Consistently, we show here that S-phase nuclei, $c d c 7$-arrested, cln-deficient, or $\alpha$-factorblocked $G_{1}$ nuclei can replicate in S-phase extract, whereas $G_{2}$ - or M-phase nuclei cannot. Initiation in $G_{1}$ phase nuclei is lost at the restrictive temperature in a conditional orc2-1 mutant. This shows clearly that ORC is required for initiation of DNA replication, resolving the ambiguity remaining from in vivo temperature shift experiments, that is, initiation events were retarded but not blocked fully until $3 \mathrm{hr}$ after the temperature shift (Liang et al. 1995), and temperature-sensitive cells arrested at restrictive temperature only slowly, with nearly a 2N DNA content (Bell et al. 1993; Micklem et al. 1993).

The demonstration that $c \ln$-deficient nuclei are able to initiate DNA replication in an S-phase extract (Fig. 4), suggests that a functional prereplication complex (pRC) is formed before activation of the $\mathrm{G}_{1}$ cyclin/Cdk complexes. This suggests that neither the second burst of Cdc6p synthesis that occurs in late $G_{1}$ (Piatti et al. 1995) nor other events promoted by $G_{1}$ cyclins, are essential $G_{1}$ events for DNA replication. In other words, even if there are post-Start events that prepare origins for initiation, these can apparently occur in the presence of $S$ phase activities, and are therefore not obligatorily $G_{1}$. specific events. These results are fully consistent with genetic studies showing that $\mathrm{Clb} 5 / \mathrm{Cdk} 1$ kinase can promote S-phase in the triple cln disruption background (Schwob and Nasmyth 1993).

\section{Candidates for SPF activity}

As demonstrated in Xenopus and a mammalian replication system (Krude et al. 1997), the formation of a pRC is insufficient to promote replication, and initiation must be catalyzed by the protein kinase-containing S-phase promoting factor (SPF; for review, see Romanowski and Madine 1996). In our yeast system, the initiation of DNA replication in $G_{1}$-phase nuclei requires an S-phase extract, which contains a 6-DMAP-sensitive activity required for promoting initiation. Replication is not only reduced in the presence of the inhibitor, but also in heatinactivated S-phase extracts, and in extracts obtained from cells blocked with pheromone in $\mathrm{G}_{1}$ (Figs. 2 and 5). The positive signal for replication may in fact require multiple events, such as the activation of Clb5/Cdkl and $\mathrm{Cdc} 7 / \mathrm{Dbf} 4$ protein kinases, and the inactivation of $\mathrm{p} 40^{\mathrm{Sic} 1}$, a specific inhibitor of the $\mathrm{Clb} / \mathrm{Cdk}$ complex (Jackson et al. 1993; Schwob and Nasmyth 1993; Schwob et al. 1994). We do not know whether $\mathrm{p} 40^{\mathrm{SICl}}$ is degraded by addition of the S-phase extract, or whether the S-phase kinase level simply overwhelms it. The enhanced levels of elongation observed in S-phase nuclei may reflect their lower levels of this kinase inhibitor, as it has been demonstrated that the mammalian Cdk inhibitor p21 represses polo activity through interaction with proliferating cell nuclear antigen (PCNA) (Waga et al. 1994; Podust et al. 1995).

Interestingly, we observed that an extract from mitotically blocked $c d c 16-1$ mutant cells is sufficient to stimulate replication in both $\mathrm{G}_{1}$ - and S-phase nuclei, suggesting that the $\mathrm{Clb} / \mathrm{Cdk} 1$ complexes present in mitosis can also trigger initiation (data not shown). This is consistent with in vivo observations showing that any of the six B-type cyclins can promote the $\mathrm{G}_{1} / \mathrm{S}$ transition (for review, see Nasmyth 1996). Because mitotic extracts have been reported to be deficient for $\mathrm{Cdc} 7$ (Jackson et al. 1993), the essential Cdc7 kinase activity may be provided in cis by the $\mathrm{G}_{1}$-phase nuclei, and perhaps activated by $\mathrm{Clb} / \mathrm{Cdk} 1$ in trans. Further analysis of extracts and nuclei from a range of kinase and cyclin mutants will determine whether $\mathrm{Cdc} 7$ and $\mathrm{Cdc} 28$ operate on the same, or on parallel pathways (see Jackson et al. 1993; Yoon et al. 1993; Hardy and Pautz 1996).

In yeast, Cdk1 (i.e., Cdc28 kinase) has a dual role in the control of DNA replication as it is involved in triggering initiation and simultaneously appears to inhibit the reestablishment of pRCs (for review, see Nasmyth 1996). We observe no replication foci when $\mathrm{G}_{2}$ - and $\mathrm{M}$-phase nuclei are added to $\mathrm{S}$-phase extracts, suggesting that either pRC assembly factors are missing, or that pRC formation is prevented by the S-phase extract. Because the orc2-1 mutation is not dominant in vivo and does not impede the binding of wild-type ORC in vitro (Bell et al. 1993), our inability to complement the orc2-1 deficiency with a wild-type S-phase extract, is consistent with the notion that $\mathrm{pRCs}$ are unable to form attributable to the S-phase Cdk1 activity. Our yeast-based replication system should now enable us to "reprogram" postreplicative nuclei in vitro, by inactivating the $\mathrm{Clb} / \mathrm{Cdk} 1 \mathrm{ki}$ - 
nases, and sequentially adding back components of the genetically-defined complexes required for the initiation of eukaryotic DNA synthesis.

\section{Materials and Methods}

\section{Yeast strains}

The yeast strain Saccharomyces cerevisiae GA-59 (MATa, leu2, trp1, ura3-52, prb1-1122, pep4::URA3, prc1-407, gal2), lacking three vacuolar proteases, was used as our standard wild type. Other strains include GA-266 (MATa, pri1-1, ura3-52, ino1, can1, pep4::URA3), provided by P. Plevani (University of Milan, Italy); GA-161 (MATa, cdc16-1, ura1, his7), originally from L. Hartwell (University of Washington, Seattle); GA-85 (MATa, his6, bar1, trp1-289, leu2-2,112, ura3-52, cdc7-1), formerly RM 14-3A from B. Brewer and W. Fangman (University of Washing-

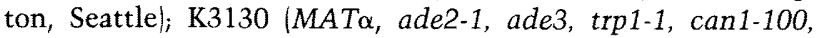
leu2-3,112, his3-11,15, ura3, GAL, cln1::hisG, cln2::del, cln3::GAL::CLN3 (URA3), CLA1 (SSD1), provided by E. Schwob (IGM, Montpellier, France); GA-361 (MATa, cdc28-1N, ade2-1, ura3-1, his3-11, trp1-1, leu2-3,112, can1-100 and GA-462 (MATa, orc2-1, ade2-1, ura3-1, his3-11, trp1-1, 1eu2-3,112, can1100 , pep4::URA3), which resulted from crossing the $c d c 28-1 \mathrm{~N}$ and orc2-1 temperature-sensitive strains into a W303 background. The replication assay works in all strain backgrounds tested to date. The pep4 yeast were tested regularly for absence of carboxypeptidase Y activity (Jones 1977). To test whether mitochondrial DNA influences our assay, the strains GA-59 and GA-462 were rendered rho $^{\circ}$. Yeast media were as described in Rose et al. (1990) and contained $2 \%$ glucose (Glu or D), raffinose (Raff), or galactose $(\mathrm{Gal})$, as indicated $\mathrm{YP}=1 \%$ yeast extract and $2 \%$ Bacto-peptone (Difco).

\section{Synchronization, isolation, and extraction of yeast nuclei}

Yeast cells were grown in YPD at $30^{\circ} \mathrm{C}$ to a density of 0.5 to $1 \times 10^{7}$ cells $/ \mathrm{ml}$. Temperature-sensitive strains were grown at $25^{\circ} \mathrm{C}\left(23^{\circ} \mathrm{C}\right.$ for orc $2-1$ and $\left.c d c 7-1\right)$ and shifted to $37^{\circ} \mathrm{C}$ for arrest. After harvesting and washing with centrifugation at $2000 \mathrm{~g}$ for 5 min at room temperature, the cells were resuspended in $1 / 4$ of the initial volume in YPD at $\mathrm{pH} 5.0$. $\alpha$-Factor was added to an optimal concentration (1.5 $\times 10^{-7} \mathrm{M}$ for the GA-59 strain). Cells were incubated at $30^{\circ} \mathrm{C}$ (or at permissive temperature) - generation time until no small buds were visible, indicating a block at the end of $G_{1}$. For S-phase extracts, cells were washed and resuspended in the same volume of YPD prewarmed to growth temperature. Release from the block was checked microscopically, and the cells were harvested as soon as small buds appeared. Spheroplasting of $\mathrm{G}_{1}$ - or S-phase cells, isolation of crude nuclei, and extraction with $\left(\mathrm{NH}_{4}\right)_{2} \mathrm{SO}_{4}$ for the replication extract are described in Verdier et al. (1990). Both Orc2 and Cdc6p, as well as the replication polymerases are extracted efficiently from nuclei with the detergents and high concentrations of ammonium sulfate used for preparing nuclear extracts (D. Braguglia, P. Pasero, B. Duncker, P. Heus, and S. Gasser, in prep.). Purification of $\beta-1,3$ glucanase was carried out according to Shen et al. (1991). For $G_{1}$ extracts, $\alpha$ factor was present during spheroplasting.

The isolation of nuclei for in vitro replication used yeast cells synchronized and spheroplasted as for nuclear extract preparation (Verdier et al. 1990). Spheroplasts were carefully resuspended at $0.2 \mathrm{~g} / \mathrm{ml}$ in $5 \mathrm{ml}$ of an ice-cold breakage-buffer (buffer $0.25 \times \mathrm{A}$, which contains $20 \mathrm{mM}$ Tris- $\mathrm{HCl}$, at $\mathrm{pH} 7.4,20 \mathrm{mM} \mathrm{KCl}$, $2 \mathrm{~mm}$ EDTA-KOH, $0.05 \mathrm{~mm}$ spermine, $0.125 \mathrm{~mm}$ spermidine, $300 \mu \mathrm{g} / \mathrm{ml}$ of benzamidine, $1 \mu \mathrm{g} / \mathrm{ml}$ of pepstatin, $0.5 \mu \mathrm{g} / \mathrm{ml}$ of leupeptin, 1\% Trasylol (aprotinin, Bayer), 0.5 mM PMSF, 1\% thiodiglycol). Usually 1 gram of spheroplasts was immediately layered over $45 \mathrm{ml}$ of a solution containing $10 \%$ sucrose in breakage buffer, and nuclei were separated by centrifugation at $2500 \mathrm{~g}$ for $20 \mathrm{~min}$ at $4^{\circ} \mathrm{C}$ in a Sorvall RC600 centrifuge. The nuclei, which sediment at the middle of the gradient, were collected and diluted by addition of 1 vol of $0.25 \times \mathrm{A}, 0.5 \mathrm{~mm}$ PMSF. Sucrose-purified nuclei were recovered by two rounds of centrifugation $\left(5000 \mathrm{~g}, 10 \mathrm{~min}\right.$ at $\left.4^{\circ} \mathrm{C}\right)$ and resuspended in a minimal volume of glycerol buffer ( $60 \%$ glycerol, $0.25 \times \mathrm{A}, 0.2 \mathrm{mM}$ PMSF) and stored at $-20^{\circ} \mathrm{C}$. Yield (generally $5 \mathrm{OD}_{260} /$ gram of spheroplast) was estimated by optical density in $1 \%$ SDS 11 $\mathrm{OD}_{260}=10^{8}$ nuclei).

The integrity of the nuclear membrane was checked using $>150-k D$ FITC dextran as described by Peters (1983). Permeabilized nuclei were prepared by incubation for $15 \mathrm{~min}$ in $0.1 \%$ Triton X-100 in $0.25 \times \mathrm{A}, 0.5 \mathrm{~mm}$ PMSF at $4^{\circ} \mathrm{C}$.

\section{In vitro replication reaction}

The 25- $\mu$ l standard reaction mixture contained $2.5 \mu \mathrm{l}$ of $10 \times$ replication buffer (120 mM HEPES-NaOH at $\mathrm{pH} 7.6,48 \mathrm{~mm}$ $\mathrm{MgCl}_{2}, 3 \mathrm{~mm}$ EDTA-NaOH at $\mathrm{pH} 7.6,6 \mathrm{~mm}$ DTT), $10^{7}$ nuclei (corresponding to $100 \mathrm{ng}$ of genomic DNA), an energy regeneration system of $40 \mathrm{~mm}$ creatine phosphate and $0.125 \mathrm{mg} / \mathrm{ml}$ of creatine kinase, $20 \mu \mathrm{M}$ of each dCTP, dGTP, dTTP, $8 \mu \mathrm{M} \mathrm{dATP,}$ $5 \mu \mathrm{Ci} / \mu \mathrm{l}\left[\alpha{ }^{32} \mathrm{P}\right] \mathrm{dATP}, 20 \mu \mathrm{M}$ of each ATP, CTP, GTP, UTP, and $60 \mu \mathrm{g}$ of protein extract. Where indicated, aphidicolin, dissolved in dimethylsulfoxide (DMSO), was added to a final concentration of $0.5 \mathrm{mg} / \mathrm{ml}$. The replication reaction was stopped after 90 $\mathrm{min}$ at $25^{\circ} \mathrm{C}$ (or as indicated) with final concentrations of $0.3 \mathrm{M}$ Na-acetate at pH 5.2, $0.1 \%$ SDS, $5 \mathrm{~mm}$ EDTA, $100 \mu \mathrm{g} / \mathrm{ml}$ of Proteinase $\mathrm{K}$, and was incubated for $60 \mathrm{~min}$ further at $37^{\circ} \mathrm{C}$. The DNA was phenol extracted, precipitated, washed with $1 \mathrm{ml}$ of $70 \%$ ethanol, dried, and resuspended in $20 \mu$ l of distilled water. All other methods were performed according to standard protocols (Sambrook et al. 1989). Replication of plasmid DNA in the soluble extract was carried out as described for nuclei, except that $300 \mathrm{ng}$ of pH4ARS DNA was used as template (D. Braguglia, P. Pasero, B. Duncker, P. Heus, and S. Gasser, in prep.). Quantitation of $\left[\alpha_{-}{ }^{32} \mathrm{P}\right] \mathrm{dATP}$ incorporation in the high-molecular-weight genomic DNA was done on dried gels by PhosphorImager scanning using serial dilutions of the $\left[\alpha-{ }^{32} \mathrm{P}\right] \mathrm{dATP}-\mathrm{label}-$ ing mixture to convert the arbitrary units of PhosphorImager readings into moles of dATP incorporated. The internal pool of dATP in the nuclei was shown by isotope dilution to vary from 8 to $15 \mu \mathrm{M}$. For immunofluorescence and confocal microscopy, biotin-16-dUTP (Boehringer Mannheim), biotin-7-dATP (BRL), and digoxigenin-11-dUTP (Boehringer Mannheim) were used for labeling. The best results were obtained with $20 \mu \mathrm{M}$ DIG-dUTP, as determined by titration.

\section{Two-dimensional gel electrophoresis and gradient centrifugation}

Two-dimensional gel electrophoresis was carried out on genomic DNA (4 $\mu \mathrm{g}$ DNA) or on nuclei replicated in vitro $(1-2 \mu \mathrm{g})$, as described by Brewer and Fangman (1987). Gels were transferred to nitrocellulose and hybridized with the 981-bp HpaI$X$ baI fragment of Yep13 (Fig. 6E) or the 2.6-kb Scal-EcoRV fragment of pRS424 (Figs. 4B,C, and 6C), both containing the $2 \mu$ ARS. Replication at the pRS424 plasmid was detected using the 1.87-kb EcoRV-ScaI fragment of pRS424, that does not contain the $2 \mu$ origin.

BrdUTP substitution in $G_{1}$ nuclei was for $180 \mathrm{~min}$ at $25^{\circ} \mathrm{C}$ in an S-phase extract with $200 \mu \mathrm{M}$ BrdUTP and all other additions as indicated above. Following phenol/chloroform extraction and the removal of unicorporated label using Nuc-Trap col- 
umns (Stratagene), the genomic DNA was digested with EcoRI, and mixed with a $\mathrm{CsCl}$ solution to a final density of 1.7176 grams $/ \mathrm{ml}$ at $25^{\circ} \mathrm{C}(\eta=1.4010)$. The gradient was generated at $35,000 \mathrm{rpm}$ in a fixed angle T1270 rotor (Sorvall) for $40 \mathrm{hr}$ at $20^{\circ} \mathrm{C}$. Fractions of $350 \mu \mathrm{l}$ were collected from the bottom of the gradient, and $\left[\alpha{ }^{32} \mathrm{P}\right] \mathrm{dATP}$ was counted in a Packard liquid scintillation counter. Gradients usually span densities from 1.6742 grams $/ \mathrm{ml}(\eta=1.3970)$ to $1.7936 \mathrm{grams} / \mathrm{ml}(\eta=1.4080)$, and heavy-light DNA is recovered between $\eta=1.4035$ and 1.4040, whereas the unsubstituted runs at $n=1.4000$ to 1.4010 . The sedimentation of the light-light and heavy-light DNA was standardized by elongating a primed M13 template with Sequenase (Boehringer Mannheim) incorporating either BrdUTP or dTTP. Quantitation of semiconservative replication was done by integrating the peak of heavy-light DNA and converting the counts per minute into moles of dATP incorporated, as described above.

\section{Immunofluorescence and confocal microscopy}

After the replication assay, yeast nuclei were fixed in $4 \%$ paraformaldehyde for $60 \mathrm{~min}$ at $4^{\circ} \mathrm{C}$, washed for $90 \mathrm{~min}$ in $1 \times$ PBS, $0.1 \%$ Triton-X100 $(\mathrm{PT})$, and air-dried on a microscope slide. ExtrAvidin-FITC (Sigma) was used to detect biotin-dUTP, and FITC-coupled anti DIG F(ab) fragment or a monoclonal antibody against DIG were used for digoxigenin. Incubation was in PT for $1.5 \mathrm{hr}$ at $37^{\circ} \mathrm{C}$, and slides were washed $6 \times 5 \mathrm{~min}$ in PT and mounted in $1 \times$ PBS, $50 \%$ glycerol, $24 \mu \mathrm{g} / \mathrm{ml}$ of 1,4 diazabicyclo$2,2,2$,octane (DABCO) with $1 \mu \mathrm{g} / \mathrm{ml}$ of EtBr. Confocal microscopy was performed on a Zeiss Axiovert 100 microscope (Zeiss Laser Scanning Microscope 410) with a $63 \times$ Plan-Apochromat objective (1.4 oil). Standardized conditions were used for image scanning, averaging, and processing. Quantitation was performed using ImageQuant software (Molecular Dynamics) or the histograms of green (FITC) and red (EtBr) channels in Adobe Photoshop after elimination of the background. Background is the low non-nuclear signal of red or green fluorescence measured in a $50 \times 50$ pixel area containing no nuclei $\mid<15 \%$ of the total signal).

\section{Acknowledgments}

We thank H. Renauld for strain construction and $\mathrm{G}_{0}$-arrested cells, P. Heun for FACs analysis, and P. Plevani, J. Li, K. Nasmyth, L. Hartwell, and E. Schwob for strains. We thank J. Diffley for the JAb12 antibody, and S.N. Slilaty for the pUV5-G1S E. coli plasmid expressing $\beta-1,3$, -glucanase. Discussions and corrections from R. Laskey, P. Plevani, J. Diffley, B. Duncker, M. Cockell, U. Hübscher, and H. Renauld are gratefully acknowledged. P.P. thanks the European Molecular Biology Organization (EMBO) for a Long-term Fellowship, and S.M.G. thanks the Swiss National Science Foundation, Human Frontiers Science Program, the Swiss Cancer League, and the Roche Research Foundation for support.

The publication costs of this article were defrayed in part by payment of page charges. This article must therefore be hereby marked "advertisement" in accordance with 18 USC section 1734 solely to indicate this fact.

\section{References}

Bell, S.P. and B. Stillman. 1992. ATP-dependent recognition of eukaryotic origins of DNA replication by a multiprotein complex. Nature 357: 128-134.

Bell, S.P., R. Kobayashi, and B. Stillman. 1993. Yeast origin rec- ognition complex functions in transcription silencing and DNA replication. Science 262: 1844-1849.

Blow, J.J. 1993. Preventing re-replication of DNA in a single cell cycle: Evidence for a replication licensing factor. J. Cell Biol. 122: 993-1002.

Blow, J.J. and R.A. Laskey. 1986. Initiation of DNA replication in nuclei and purified DNA by a cell-free extract of Xenopus eggs. Cell 47: 577-587.

-1988. A role for the nuclear envelope in controlling DNA replication within the cell cycle. Nature 332: 546-548.

Brewer, B.J. and W.L. Fangman. 1987. The localization of replication origins on ARS plasmids in $S$. cerevisiae. Cell 51: $463-471$.

Campbell, J.L. and C.S. Newlon. 1991. In The molecular and cellular biology of the yeast Saccharomyces cerevisiae: Genome dynamics, protein synthesis, and energetics. \{ed. J.R. Broach, J.R. Pringle, and E.W. Jones. Vol. 1, pp. 41-146. Cold Spring Harbor Laboratory Press, Cold Spring Harbor, NY.

Carpenter, P.B., P.R. Mueller, and W.G. Dunphy. 1996. Role for a Xenopus Orc2-related protein in controlling DNA replication. Nature 379: 357-360.

Cocker, J.H., S. Piatti, C. Santocanale, K. Nasmyth, and J.F. Diffley. 1996. An essential role for the Cdc6 protein in forming the pre-replicative complexes of budding yeast. Nature 379: 180-182.

Coleman, T.R., P.B. Carpenter, and W.G. Dunphy. 1996. The Xenopus Cdc6 protein is essential for the initiation of a single round of DNA replication in cell-free extracts. Cell 87: 53-63.

Coverley, D. and R.A. Laskey. 1994. Regulation of eukaryotic DNA replication. Annu. Rev. Biochem. 63: 745-776.

Cox, L.S. and R.A. Laskey. 1991. DNA replication occurs at discrete sites in pseudonuclei assembled from purified DNA in vitro. Cell 66: 271-275.

Cross, F. 1990. Cell cycle arrest caused by CLN gene deficiency in Saccharomyces cerevisiae resembles START-I arrest and is independent of the mating-pheromone signaling pathway. Mol. Cell Biol. 10: 6482-6490.

Diffley, J.F., J.H. Cocker, S.J. Dowell, and A. Rowley. 1994. Two steps in the assembly of complexes at yeast replication origins in vivo. Cell 78: 303-316.

Donovan, S. and J.F.X. Diffley. 1996 Replication origins in eukaryotes. Curr. Op. Genet. Dev. 6: 203-207.

Fangman, W.L. and B.J. Brewer. 1991. Activation of replication origins within yeast chromosomes. Annu. Rev. Cell Biol. 7: 375-402.

Fox, C.A., S. Loo, A. Dillin, and J. Rine. 1995. The origin recognition complex has essential functions in transcriptional silencing and chromosomal replication. Genes \& Dev. 9: 911-924.

Francesconi, S., M.P. Longhese, A. Piseri, C. Santocanale, G. Lucchini, and P. Plevani. 1991. Mutations in conserved yeast DNA primase domains impair DNA replication in vivo. Proc. Natl. Acad. Sci. 88: 3877-3881.

Gilbert, D.M., H. Miyazawa, and M.L. DePamphilis. 1995. Sitespecific initiation of DNA replication in Xenopus egg extract requires nuclear structure. Mol. Cell. Biol. 15: 29422954.

Grallert, B. and P. Nurse. 1996. The ORC1 homolog orp1 in fission yeast plays a key role in regulating onset of S-phase. Genes \& Dev. 10: 2644-2654.

Hamlin, J.L. and P.A. Dijkwel. 1995. On the nature of replication origins in higher eukaryotes. Curr. Opin. Genet. Dev. 5: 153-161.

Hardy, F.J.C. and A. Pautz. 1996. A novel role for Cdc5p in DNA replication. Mol. Cell. Biol. 16: 6775-6782. 
Heichman, K.A. 1996. Cdc6 and DNA replication: Limited to humble origins. BioEssays 18: 859-862.

Heichman, K.A. and J.M. Roberts. 1996. The Yeast CDC16 and $C D C 27$ genes restrict DNA replication to once per cell cycle. Cell 85: 39-48.

Huberman, J.A., L.D. Spotila, K.A. Nawotka, S.M. el-Assouli, and L.R. Davis. 1987. The in vivo replication origin of the yeast $2 \mu \mathrm{m}$ plasmid. Cell 51: 473-481.

Hyrien, O. and M. Méchali. 1992. Plasmid replication in Xenopus eggs and egg extracts: A 2D gel electrophoretic analysis. Nucleic Acids Res. 20: 1463-1469.

Jackson, A.L., P.M.B. Pahl, K. Harrison, J. Rosamond, and R.A. Sclafani. 1993. Cell cycle regulation of the yeast Cdc7 protein kinase by association with the Dbf4 protein. Mol. Cell. Biol. 13: 2899-2908.

Jones, E.W. 1977. Proteinase mutants of $S$. cerevisiae. Genetics 85: 23-33.

Kearsey, S.E., K. Labib, and D. Maiorano. 1996. Cell cycle control of eukaryotic DNA replication. Curr. Opin. Genet. Dev. 6: 208-214.

Krude, T., M. Jackman, J. Pines, and R.A. Laskey. 1997. Cyclin/ Cdk-dependent initiation of DNA replication in a human cell-free system. Cell 88: 109-119.

Leno, G.H., C.S. Downes, and R.A. Laskey. 1992. The nuclear membrane prevents replication of human $G_{2}$ nuclei but not $\mathrm{G}_{1}$ nuclei in Xenopus egg extract. Cell 69: 151-158.

Levac, P. and T. Moss. 1996. Inactivation of topoisomerase I or II may lead to recombination or to aberrant replication termination on both SV40 and yeast $2 \mu \mathrm{m}$ DNA. Chromosoma 105: $250-260$.

Liang, C., M. Weinreich, and B. Stillman. 1995. ORC and Cdc6p interact and determine the frequency of initiation of DNA replication in the genome. Cell 81: 667-676.

Meijer, L. and P. Pondaven. 1988. Cyclic activation of histone $\mathrm{H} 1$ kinase during sea urchin egg mitotic divisions. Exp. Cell. Res. 174: 116-129.

Micklem, G., A. Rowley, J. Harwood, K. Nasmyth, and J.F. Diffley. 1993. Yeast origin recognition complex is involved in DNA replication and transcriptional silencing. Nature 366: 87-89.

Muzi-Falconi, M., G.W. Brown, and T. Kelly. 1996. Controlling initiation during the cell cycle. Curr. Biol. 6: 229-233.

Nakamura, H., T. Morita, and C. Sato. 1986. Structural organizations of replicon domains during DNA synthetic phase in the mammalian nucleus. Exp. Cell Res. 165: 291-297.

Nasmyth, K. 1996. At the heart of the budding yeast cell cycle. Trends Genet. 12: 405-412.

Newport, J. and H. Yan. 1996. Organization of DNA into foci during replication. Curr. Opin. Cell Biol. 8: 365-368.

Peters, R. 1983. Nuclear envelope permeability measured by fluorescence microphotolysis of single liver cell nuclei. $J$. Biol. Chem. 258: 11427-11429.

Piatti, S., C. Lengauer, and K. Nasmyth. 1995. Cdc6 is an unstable protein whose de novo synthesis in $G_{1}$ is important for the onset of $S$ phase and for preventing a "reductional" anaphase in the budding yeast Saccharomyces cerevisiae. EMBO I. 14: 3788-3799.

Piatti, S., T. Böhm, J.H. Cocker, J.F.X. Diffley, and K. Nasmyth. 1996. Activation of S-phase-promoting CDKs in late $G_{1}$ defines a "point of no return" after which Cdc6 synthesis cannot promote DNA replication in yeast. Genes \& Dev. 10: $1516-1526$.

Podust, V.N., L.M. Podust, F. Goubin, B. Ducommun, and U. Hübscher. 1995. Mechanism of inhibition of proliferating cell nuclear antigen-dependent DNA synthesis by the cyclin-dependent kinase inhibitor p21. Biochemistry 34: 8869-75.
Rao, P.N. and R.T. Johnson. 1970. Mammalian cell fusion: Studies on the regulation of DNA synthesis and mitosis. Nature 225: $159-164$.

Romanowski, P. and M.A. Madine. 1996. Mechanisms restricting DNA replication to once per cell cycle: MCMs, pre-replicative complexes and kinases. Trends Cell Biol. 6: 184188.

Romanowski, P., M.A. Madine, A. Rowles, J.J. Blow, and R.A. Laskey. 1996. The Xenopus origin recognition complex is essential for DNA replication and MCM binding to chromatin. Curr. Biol. 6: 1416-1425.

Rose, M.D., F. Winston, and P. Hieter. 1990. Methods in yeast genetics. Cold Spring Harbor Laboratory Press, Cold Spring Harbor, NY

Rowles, A., J.P. Chong, L. Brown, M. Howell, G.I. Evan, and J.J. Blow. 1996. Interaction between the origin recognition complex and the replication licensing system in Xenopus. Cell 87: 287-296.

Sambrook, J., E.F. Fritsch, and T. Maniatis. 1989. Cold Spring Harbor Laboratory, Cold Spring Harbor, New York.

Schwob, E. and K. Nasmyth. 1993. CLB5 and CLB6, a new pair of B cyclins involved in DNA replication in Saccharomyces cerevisiae. Genes \& Dev. 7: 1160-1175.

Schwob, E., T. Bohm, M.D. Mendenhall, and K. Nasmyth. 1994. The B-type cyclin kinase inhibitor $\mathrm{p} 40^{\mathrm{SICl}}$ controls the $\mathrm{G}_{1}$ to $S$ transition in S.cerevisiae. Cell 79: 233-244.

Shen, S.H., P. Chretien, L. Bastien, and S.N. Slilaty. 1991. Primary sequence of the glucanase gene from Oerskovia xanthineolytica. Expression and purification of the enzyme from Escherichia coli. J. Biol. Chem. 266: 1058-1063.

Sikorski, R.S., M. Boguski, M. Goebl, and P. Hieter. 1990. A repeating amino acid motif in CDC23 defines a family of proteins and a new relationship among genes required for mitosis and RNA synthesis. Cell 60: 307-317.

Surana, U., H. Robitsch, C. Price, T. Schuster, I. Fitch, A.B. Futcher, and K. Nasmyth. 1991. The role of CDC28 and cyclins during mitosis in the budding yeast $S$. cerevisiae. Cell 65: 145-161.

Tye, B.K. 1994. The MCM2-3-5 proteins: Are they replication licensing factors? Trends Cell Biol. 4: 160-164.

Verdier, J.M., R. Stalder, M. Roberge, B. Amati, A. Sentenac, and S.M. Gasser. 1990. Preparation and characterization of yeast nuclear extracts for efficient RNA polymerase B (II)dependent transcription in vitro. Nucleic Acids Res. 18: 7033-7039.

Waga, S., G.J. Hannon, D. Beach, and B. Stillman. 1994. The p21 inhibitor of cyclin-dependent kinases controls DNA replication by interaction with PCNA. Nature 369: 574-578.

Wu, J.R. and D.M. Gilbert. 1996. A distinct $\mathrm{G}_{1}$ step required to specify the Chinese hamster DHFR replication origin. Science 271: 1270-1272.

Yoon, H.-J., S. Loo, and J.L. Campbell. 1993. Regulation of S. cerevisiae $C D C 7$ function during the cell cycle. Mol. Biol. Cell 4: 195-208. 


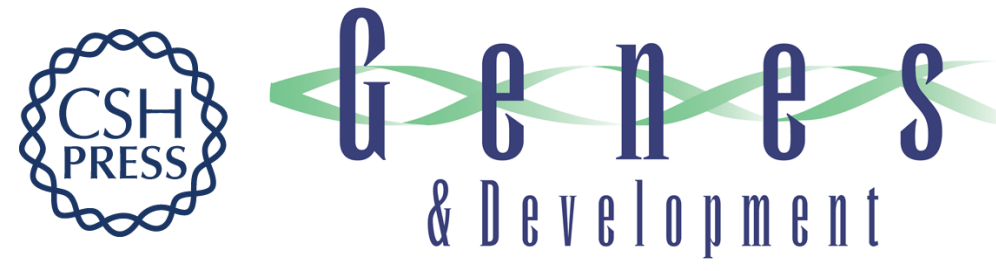

\section{ORC-dependent and origin-specific initiation of DNA replication at defined foci in isolated yeast nuclei.}

P Pasero, D Braguglia and S M Gasser

Genes Dev. 1997, 11:

Access the most recent version at doi:10.1101/gad.11.12.1504

References This article cites 56 articles, 16 of which can be accessed free at:

http://genesdev.cshlp.org/content/11/12/1504.full.html\#ref-list-1

License

Email Alerting

Service

Receive free email alerts when new articles cite this article - sign up in the box at the top right corner of the article or click here.

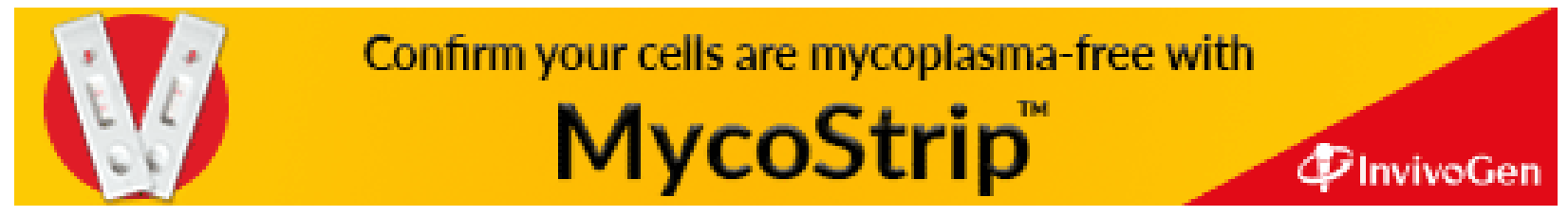

